Article

\title{
Insights into the Influence of Membrane Permeability and Structure on Osmotically-Driven Membrane Processes
}

\author{
Jing Wei ${ }^{1,2,3}$, Qianhong She ${ }^{3,4, *}$ and Xin Liu ${ }^{3}$ \\ 1 School of the Environment and Safety Engineering, Jiangsu University, 301 Xuefu Road, \\ Zhenjiang 212013, Jiangsu, China; weijing@ujs.edu.cn \\ 2 Institute of Environmental Health and Ecological Security, Jiangsu University, 301 Xuefu Road, \\ Zhenjiang 212013, Jiangsu, China \\ 3 Singapore Membrane Technology Centre, Nanyang Technological University, 1 Cleantech Loop, \\ Singapore 637141, Singapore; liux5@sustc.edu.cn \\ 4 School of Civil and Environmental Engineering, Nanyang Technological University, 50 Nanyang Avenue, \\ Singapore 639798, Singapore \\ * Correspondence: qhshe@ntu.edu.sg
}

Citation: Wei, J.; She, Q.; Liu, X. Insights into the Influence of Membrane Permeability and Structure on Osmotically-Driven Membrane Processes. Membranes 2021, 11, 153. https://doi.org/ $10.3390 /$ membranes 11020153

Academic Editor: Jose Luis Cortina Pallas

Received: 15 January 2021

Accepted: 11 February 2021

Published: 22 February 2021

Publisher's Note: MDPI stays neutral with regard to jurisdictional claims in published maps and institutional affiliations.

Copyright: (c) 2021 by the authors. Licensee MDPI, Basel, Switzerland. This article is an open access article distributed under the terms and conditions of the Creative Commons Attribution (CC BY) license (https:/ / creativecommons.org/licenses/by/ $4.0 /)$.

\begin{abstract}
The success of osmotically-driven membrane (OM) technology relies critically on highperformance membranes. Yet trade-off of membrane properties, often further complicated by the strongly non-linear dependence of OM performance on them, imposes important constraint on membrane performance. This work systematically characterized four typical commercial osmotic membranes in terms of intrinsic separation parameters, structure and surface properties. The osmotic separation performance and membrane scaling behavior of these membranes were evaluated to elucidate the interrelationship of these properties. Experimental results revealed that membranes with smaller structural parameter $(S)$ and higher water/solute selectivity underwent lower internal concentration polarization (ICP) and exhibited higher forward osmosis (FO) efficiency (i.e., higher ratio of experimental water flux over theoretical water flux). Under the condition with low ICP, membrane water permeability $(A)$ had dominant effect on water flux. In this case, the investigated thin film composite membrane (TFC, $A=2.56 \mathrm{~L} /\left(\mathrm{m}^{2} \mathrm{~h}\right.$ bar), $S=1.14 \mathrm{~mm}$ ) achieved a water flux up to $82 \%$ higher than that of the asymmetric cellulose triacetate membrane (CTA-W $(\mathrm{P}), A=1.06 \mathrm{~L} /\left(\mathrm{m}^{2} \mathrm{~h}\right.$ bar $)$, $S=0.73 \mathrm{~mm}$ ). In contrast, water flux became less dependent on the $A$ value but was affected more by membrane structure under the condition with severe ICP, and the membrane exhibited lower FO efficiency. The ratio of water flux $\left(J_{v T F C} / J_{v} C T A-W(P)\right)$ decreased to 0.55 when $0.5 \mathrm{M} \mathrm{NaCl}$ feed solution and $2 \mathrm{M} \mathrm{NaCl}$ draw solution were used. A framework was proposed to evaluate the governing factors under different conditions and to provide insights into the membrane optimization for targeted OM applications.
\end{abstract}

Keywords: osmotically-driven membrane process; internal concentration polarization; forward osmosis efficiency; permeability; structure

\section{Introduction}

Osmotically-driven membrane (OM) technologies, e.g., forward osmosis (FO) and pressure-retarded osmosis (PRO), have received much attention, largely fueled by the development of commercial FO membranes with high water flux in the last decade. In an OM process, a semi-permeable membrane is used to separate a high concentration solution (draw solution, DS) and a low concentration solution (feed solution, FS) (Figure 1). Water flux from FS to DS is driven by the osmotic pressure difference $(\Delta \pi)$. Components in FS can be retained and concentrated, whereas water passing through the membrane can be recovered from the diluted DS by a re-concentration step if required. Niche applications using DSs without the need of regeneration (e.g., seawater [1], desalination brine [2], or fertilizer solutions [3]) are attractive due to the elimination of energy-intensive DS reconcentration step. OM and hybrid OM processes have been explored for diverse fields [4], 
such as wastewater reuse [5-7], desalination [8-11], osmotic membrane bioreactor [12], energy production [13-15], and food processing [16,17].

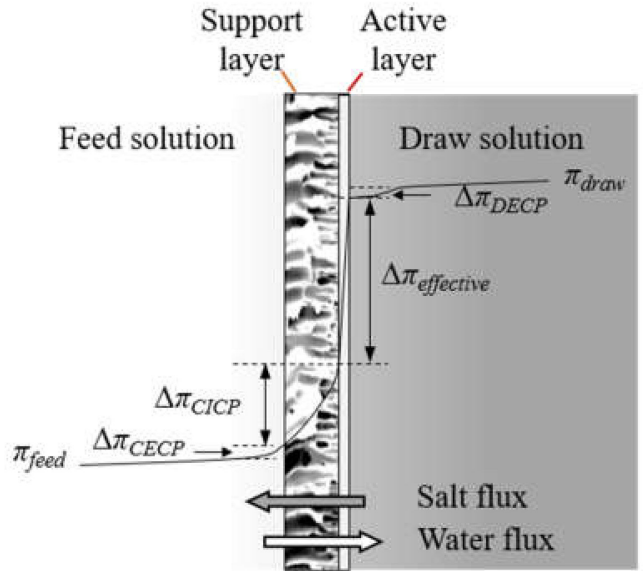

(a)

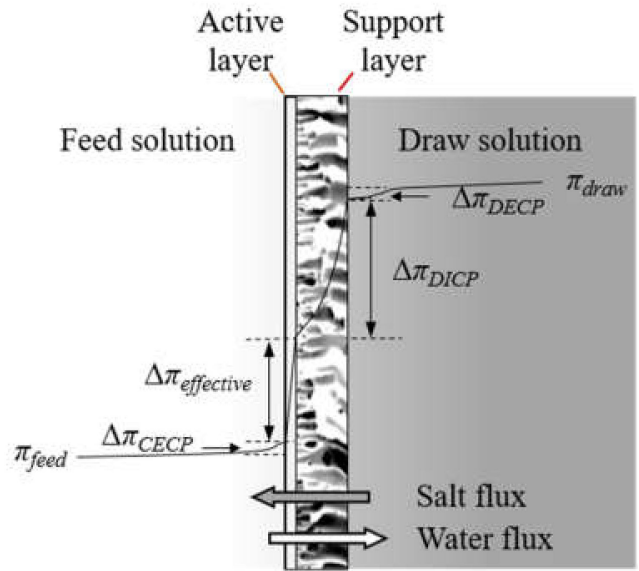

(b)

Figure 1. Schematic illustration of osmotic pressure profile across the membrane in osmotically-driven membrane processes. (a) Active-layer-facing-draw-solution (AL-DS) mode. (b) Active-layer-facing-feed-solution (AL-FS) mode. $\Delta \pi_{\text {effective }}$ is the effective osmotic pressure difference. $\Delta \pi_{C I C P}, \Delta \pi_{D I C P}, \Delta \pi_{C E C P}$, and $\Delta \pi_{D E C P}$ are the osmotic pressure difference loss caused by concentrative internal concentration polarization (ICP), dilutive ICP, concentrative external concentration polarization (ECP), and dilutive ECP [18].

High-performance membranes are crucial for OM technologies. Typical osmotic membranes consist of an active rejection layer and a porous support layer. The support layer, usually orders of magnitude thicker than the ultrathin active layer, hinders the mass transfer within membrane and causes internal concentration polarization (ICP) (Figure 1). Performance of membranes are often limited by ICP that reduces the effective osmotic pressure difference across the active layer $[19,20]$. Concentrative ICP of feed solutes occurs in the active-layer-facing-draw-solution (AL-DS) orientation, and dilutive ICP of draw solutes occurs in the active-layer-facing-feed-solution (AL-FS) orientation [21]. If the membranes have low rejection, reverse diffusion of draw solutes into the FS can further enhance ICP [22]. Due to the ICP phenomenon, membranes with a compact support layer (e.g., those used for reverse osmosis (RO) and nanofiltration (NF)) usually exhibit very low water flux in OM tests.

Some promising membranes for OM process have been developed in recent years. Membranes for FO processes were first commercialized by Hydration Technology Innovations (HTI, formerly Osmotek, Albany, OR, USA) [23]. Their first generation of membranes were flat-sheet cellulose triacetate (CTA) integral asymmetric membranes [24]. These membranes showed superior FO water flux compared to commercial RO membranes, and they have been widely used in OM study. CTA hollow fiber FO and PRO membranes have been developed by Toyobo (Osaka, Japan) $[25,26]$. Commercial thin film composite (TFC) FO membranes were also provided by a few companies, including HTI [27], Oasys Water (Boston, MA, USA) [28], Toray Chemical Korea (Seoul, Korea) [29], Woongjin Chemical (Seoul, Korea) [30], Porifera Inc. (San Leandro, CA, USA) [31], Aquaporin (Kongens Lyngby, Denmark) [32,33], etc. In parallel, considerable studies of lab-scale membrane fabrication have been reported [34-36]. These membranes had different structures, e.g., integral asymmetric membrane [37,38], TFC membrane [39-41], double-skinned membrane [42], dual-layer membrane [43], etc. According to the water and salt permeability, these membranes can be classified into RO-like [39,40], NF-like [22,44,45], and ultrafiltration (UF)-like [46] membranes. Generally, the criteria of high-performance OM membranes include high water permeability $(A)$, low solute permeability $(B)$, and small structural parameter $(S)$, as well as other properties, such as fouling resistance and mechanical strength. 
Nevertheless, improvement of OM performance is constrained by the strong trade-off among these parameters [47] (e.g., $A$ and $B$ ), and it is further complicated by its non-linear dependence on membrane properties and FS/DS concentrations [22]. Consequently, membrane optimization and selection shall be based on a set of comprehensive criteria, as well as understanding of the dominant mechanisms that govern the OM performance.

The objectives of this work were to study the influence of membrane permeability and structure on OM performance and to develop efficient strategies for OM flux enhancement. Commercial FO membranes with different structure, separation property and chemical property were systematically characterized to study the trade-off of key membrane properties. According to the FS and DS sources in potential applications, a series of OM experiments were conducted to assess the advantages and drawbacks of these membranes. The OM performance especially the water flux and FO efficiency of membranes were evaluated and compared. Membranes reported in the FO literature were also investigated to validate the comprehensive influence of membrane permeability and structure on water flux. Based on this study, a framework was developed to identify the factors that govern OM flux under different testing conditions, and to provide implications for the evaluation and optimization of membranes in OM processes.

\section{Materials and Methods}

\subsection{Membranes and Chemicals}

Four flat-sheet FO membranes, i.e., TFC, CTA-W(P), CTA-W, and CTA-NW were received from Hydration Technology Innovations (HTI, Albany, OR, USA), which are still commercially available from Fluid Technology Solutions, Inc. $\left(\mathrm{FTSH}_{2} \mathrm{O}\right.$, Albany, OR, USA) [48]. According to the manufacturer, the thin film composite membrane (referred to as TFC) had a mesh embedded in the substrate. Two of the integral asymmetric membranes (referred to as CTA-W(P) and CTA-W) had an embedded woven mesh. The integral asymmetric membrane with a nonwoven fabric was referred to as CTA-NW. All the membranes were stored in pure water before characterization.

Sodium chloride $(\mathrm{NaCl})$, sodium sulfate $\left(\mathrm{Na}_{2} \mathrm{SO}_{4}\right)$ and calcium chloride $\left(\mathrm{CaCl}_{2}\right)$ for OM tests were purchased from Merck (Darmstadt, Germany). All chemicals were analytical grade and were used as received. Ultrapure water with resistivity of $18.2 \mathrm{M} \Omega \cdot \mathrm{cm}$ was supplied by a Milli-Q water system (Milli-pore, Darmstadt, Germany).

\subsection{Membrane Characterization}

\subsubsection{Characterization of Membrane Structure, Morphology and Chemical Property}

Membrane structure and morphology were observed by field-emission scanning electron microscopy (FESEM, JSM-7600F, JEOL, Akishima, Japan). The membranes were freeze-dried before characterization. Samples were sputter coated a thin layer of platinum before FESEM scanning. The images were obtained with secondary electrons at $5.0 \mathrm{kV}$. Chemical compositions of membranes were characterized by Fourier transform infrared spectroscopy (FTIR, Spectrum 2000 FTIR Spectrometer, PerkinElmer, Boston, MA, USA) in attenuated total reflectance (ATR) mode. Porosity of membranes was evaluated by gravimetric method. Membrane samples were saturated with water and then thoroughly dried. The wet mass and dry mass were measured to calculate the porosity in accordance to previous work [24]. Surface roughness of membranes was characterized by atomic force microscopy (AFM, XE-100, Park Systems, Suwon, Korea). The root mean squared roughness $\left(R_{q}\right)$ of membrane rejection layer was reported. Water contact angles of membranes were measured by static sessile drop method using a contact angle system (OCA, Dataphysics, Filderstadt, Germany). Mechanical strength of membranes was measured using a tensile testing system (Instron 5567, Norwood, MA, USA). For membranes with a mesh as reinforcing layer (TFC, CTA-W(P), and CTA-W), tensile testing was performed with tension in both the axial direction along filaments and the diagonal direction of mesh opening. 


\subsubsection{Measurement of Membrane Permeability}

The water and salt permeabilities of membranes were determined in a cross-flow RO filtration setup (Figure S1). The temperature of feed was maintained at $23 \pm 1{ }^{\circ} \mathrm{C}$ and the feed pressure was 5 bar for all tests. Water permeability coefficient $(A)$ was measured using pure water as feed. To measure the salt rejection of membrane, $10 \mathrm{mM} \mathrm{NaCl}$ or 10 $\mathrm{mM} \mathrm{Na} 2 \mathrm{SO}_{4}$ solutions were used as feeds. The concentrations of feed and permeate were measured using a conductivity meter (UltraMeter II ${ }^{\mathrm{TM}} 4 \mathrm{P}$, Myron L Company, Carlsbad, CA, USA) to calculate the salt rejection $(R)$ and salt permeability coefficient $(B)$ [22]. The $A$, $R$, and $B$ values of membranes were calculated according to:

$$
\begin{gathered}
A=\frac{J}{\Delta P^{\prime}} \\
R=\frac{C_{f}-C_{p}}{C_{f}} \times 100 \%, \\
B=\left(\frac{1}{R}-1\right) \times J,
\end{gathered}
$$

where $J$ is the flux of permeate; $\Delta P$ is the transmembrane pressure; $C_{f}$ and $C_{p}$ are the salt concentrations of feed and permeate, respectively.

\subsubsection{Evaluation of OM Performance}

FO performance of membranes were evaluated in a cross-flow FO setup in both AL-DS and AL-FS orientations in accordance to previous studies [22,24]. $\mathrm{NaCl}$ solutions with concentrations of $0,10 \mathrm{mM}$, and $0.5 \mathrm{M}$ were used as FS to simulate pure water, freshwater and seawater. $\mathrm{NaCl}$ solutions with concentrations of $0.2 \mathrm{M}, 0.5 \mathrm{M}$, and $2 \mathrm{M}$ were used as DS to simulate brackish water, seawater, and high-salinity brine. A cross-flow velocity of $23.2 \mathrm{~cm} / \mathrm{s}$ was applied to both FS and DS channels. Water flux $\left(J_{v}\right)$ and salt flux $\left(J_{s}\right)$ was calculated as the permeate rate of water and salt per unit of membrane area [22,24]. FO efficiency $\left(J_{v} / J_{v}\right.$ Theo $)$ was calculated as the ratio of experimental FO water flux over the theoretical water flux $\left(J_{v}\right.$ Theo $\left.=A \Delta \pi\right)$ that can be achieved when there was no concentration polarization. Mass transfer coefficient $\left(K_{m}\right)$ and structural parameter $(S)$ of membranes were calculated according to the ICP model [49], as follows:

$$
\begin{gathered}
\mathrm{AL}-\mathrm{DS}: J_{v}=K_{m} \ln \frac{\pi_{\text {draw }}-\frac{I_{v}}{A}+\frac{B}{A}}{\pi_{\text {feed }}+\frac{B}{A}}, \\
\mathrm{AL}-\mathrm{FS}: J_{v}=K_{m} \ln \frac{\pi_{\text {draw }}+\frac{B}{A}}{\pi_{\text {feed }}+\frac{I_{v}}{A}+\frac{B}{A}}, \\
K_{m}=\frac{D}{S},
\end{gathered}
$$

where $\pi_{\text {draw }}$ and $\pi_{\text {feed }}$ are the osmotic pressures of DS and FS, respectively; $D$ is the diffusion coefficient of solute.

FO scaling experiments were conducted using gypsum as a model scalant. The tests were performed in the AL-FS mode. This mode is preferred in FO applications with low scaling/fouling potential as it can eliminate the internal clogging of support layer and achieve more stable flux in long-term operation [50]. In the scaling tests, mixed solution containing $\mathrm{Na}_{2} \mathrm{SO}_{4}(72 \mathrm{mM}), \mathrm{CaCl}_{2}(26.1 \mathrm{mM})$, and $\mathrm{NaCl}(10 \mathrm{mM})$ was used as $\mathrm{FS}$, of which the gypsum saturation index (SI) was 2.0 [51]. Baseline tests were performed using $0.163 \mathrm{M}$ $\mathrm{NaCl} \mathrm{FS}$, of which the SI was 0 and the osmotic pressure ( $7.5 \mathrm{bar}$ ) was similar with that of scaling test. DS with concentration of $2-3 \mathrm{M} \mathrm{NaCl}$ was used to adjust initial $J_{v}$ to a moderate value of $15 \mathrm{~L} /\left(\mathrm{m}^{2} \mathrm{~h}\right)$ for each test. A cross-flow velocity of $23.2 \mathrm{~cm} / \mathrm{s}$ was applied to FS and DS channels. 
PRO tests were performed in a cross-flow PRO setup as in reference [52]. Membrane coupons were loaded in membrane cell with AL-DS orientation. Net-type spacers were placed on both the FS and DS sides of membrane. $1 \mathrm{M} \mathrm{NaCl}$ was used as DS to simulate seawater desalination brine, and was circulated by a high-pressure pump, while $10 \mathrm{mM}$ $\mathrm{NaCl} F S$ was circulated without pressurization. Draw pressure $\left(P_{\text {draw }}\right)$ was increased in steps of approximately 3 bar, until the peak power density was reached. Pressure at FS side $\left(P_{\text {feed }}\right)$ was also monitored to calculate the pressure difference $\left(\Delta P=P_{\text {draw }}-P_{\text {feed }}\right)$. During PRO tests, pure water was dosed into FS to maintain a constant feed volume. $J_{v}$ and $J_{s}$ at each pressure were measured as the water and salt permeate rate per unit of membrane area. Power density $(W)$ of membrane was calculated as:

$$
\mathrm{W}=J_{v} \times \Delta P .
$$

\section{Results and Discussions}

\subsection{Structure, Morphology, and Chemical Property of Membranes}

Morphology of the membranes was characterized using FESEM and AFM. TFC had a three-layer structure (Figure 2a): (1) a polyamide (PA) top layer featured with a ridgeand-valley surface morphology (Figure 2b,c) and characteristic FTIR peaks at $1659 \mathrm{~cm}^{-1}$ (amide I band), $1609 \mathrm{~cm}^{-1}$ (aromatic amide) and $1549 \mathrm{~cm}^{-1}$ (amide II band) [53] (Figure 3a), (2) a polysulfone (PSf) support layer with finger-like pore structure, and (3) a polyester (PET) mesh embedded at the bottom of PSf layer for mechanical reinforcement. The thin and porous support layer (thickness of $105 \mu \mathrm{m}$ and porosity of $66 \%$, Table 1 ) resulted in a small $S$ value $(1.14 \mathrm{~mm})$, which was an order of magnitude smaller than that of typical commercial TFC RO membranes [24].

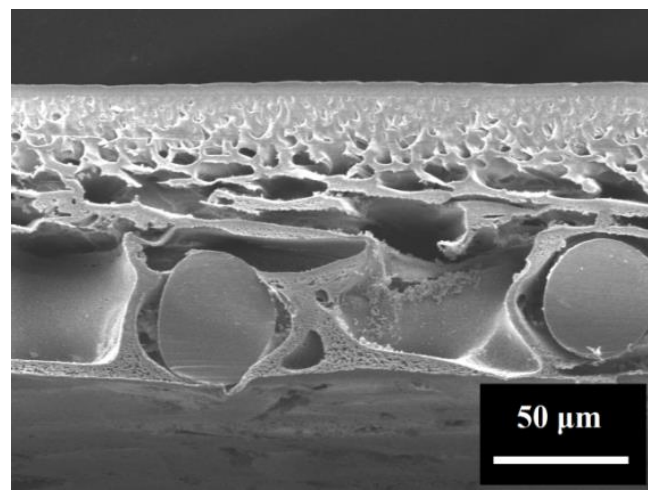

(a)

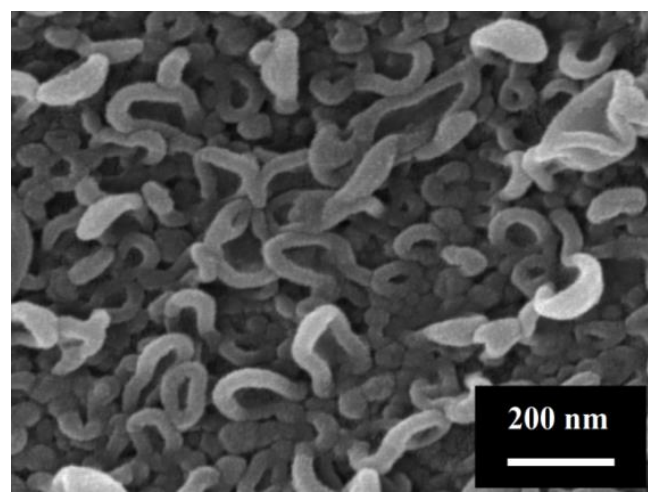

(b)

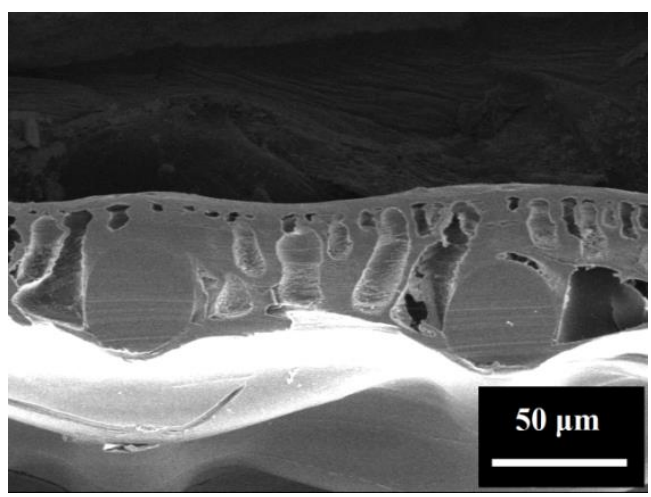

(d)

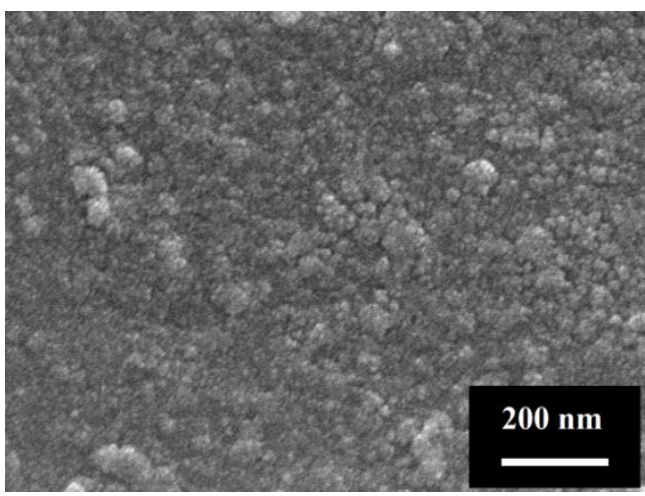

(e)

Figure 2. Cont. 


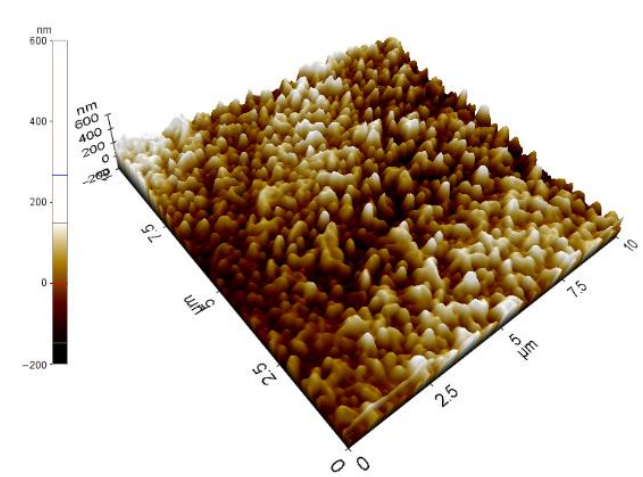

(c)

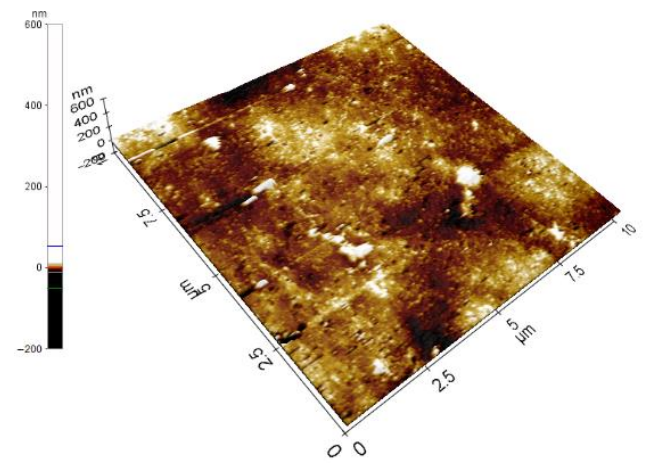

(f)

Figure 2. Structure and surface morphology of the thin film composite membrane (TFC) and cellulose triacetate membrane (CTA-W(P)). (a) Field-emission scanning electron microscopy (FESEM) micrograph of TFC cross-section at 500 $\times$. (b) FESEM micrograph of the surface of TFC active layer at 100,000×. (c) Atomic force microscopy (AFM) image of the surface of TFC active layer. (d) FESEM micrograph of CTA-W(P) cross-section at 500 $\times$. (e) FESEM micrograph of the surface of CTA-W(P) active layer at $100,000 \times$. (f) AFM image of the surface of CTA-W(P) active layer.

According to the FTIR results, CTA-W(P), CTA-W, and CTA-NW were all prepared with cellulose triacetate (Figure $3 b$ ). These membranes had smoother surfaces compared to the polyamide-based TFC. CTA-W(P) was an integral asymmetric membrane with a woven PET mesh embedded in the CTA layer (Figure 2d). Its CTA layer with finger-like pore structure had similar porosity $(62 \%)$ but smaller thickness $(52-71 \mu \mathrm{m})$ compared to TFC. Consequently, CTA-W(P) had a smaller $S$ value of $0.73 \mathrm{~mm}$. Structural property of CTA-W and CTA-NW had been reported in our previous study [24]. FESEM micrographs of their cross-sections can be found in Appendix A (Figure A1). CTA-W had a similar structure as CTA-W(P) with the same type of woven PET mesh embedded in support layer. However, CTA-W had a thinner and less porous CTA layer without macrovoid (Figure A1a). The $S$ value of CTA-W $(0.82 \mathrm{~mm})$ was slightly higher than that of CTA-W $(\mathrm{P})$. Different from CTA-W(P) and CTA-W, CTA-NW was reinforced by a nonwoven fabric attached at the bottom of CTA layer (Figure A1b). To mitigate ICP, the nonwoven fabric of CTA-NW was much looser compared to those used in commercial RO membranes. The CTA layer of CTA-NW had similar thickness $(\sim 60 \mu \mathrm{m})$ but less porous finger-like pore structure compared to CTA-W(P). Due to the large total membrane thickness $(129 \mu \mathrm{m})$, CTA-NW had the largest $S$ value $(1.77 \mathrm{~mm})$ of the four membranes.

Mechanical property of the membranes was characterized by tensile testing. Due to the porous structure, the mechanical strengths of PSf and CTA support layers were lower than the intrinsic values of bulk polymers. The membranes were strengthened by reinforcing fabric. The efficiency of fabric reinforcement depended on the orientation of fabric filaments. For membranes reinforced by plain woven mesh (TFC, CTA-W(P), and CTA-W), tensile tests were conducted at both axial and diagonal directions, as illustrated in Figure A2 in Appendix B. Membranes showed higher Young's moduli and less strain at the point of break when tension was applied in the axial direction of mesh filaments (Table 1), implying a stronger reinforcement effect in this direction. For membrane reinforced by nonwoven fabric (CTA-NW), repeated measurements were conducted with tension at random directions. It showed isotropic mechanical property due to the randomly orientated filaments of nonwoven fabric. TFC membranes for pressure-driven process usually consist of a more compact nonwoven reinforcing fabric to reduce anisotropic stress and membrane deformation. The TFC FO membrane in this study showed compromised mechanical strength, as a result of the higher porosity and macrovoids in the PSf layer, as well as the mesh support (Figure 2a). Trade-off between mechanical strength and $S$ value was also observed in the CTA membranes. For example, CTA-W with a dense support layer can stand higher stress at the point of break than CTA-W(P); however, it also resulted in a slightly larger $S$ value. 


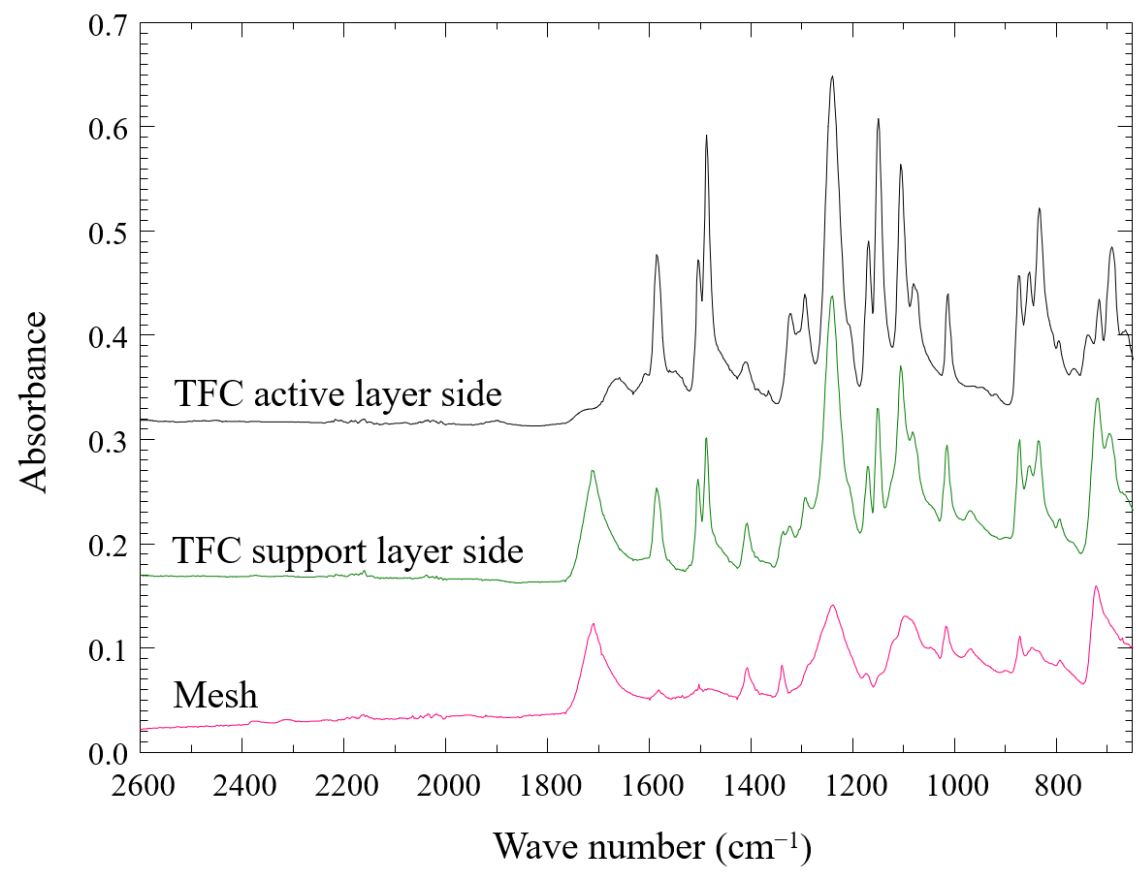

(a)

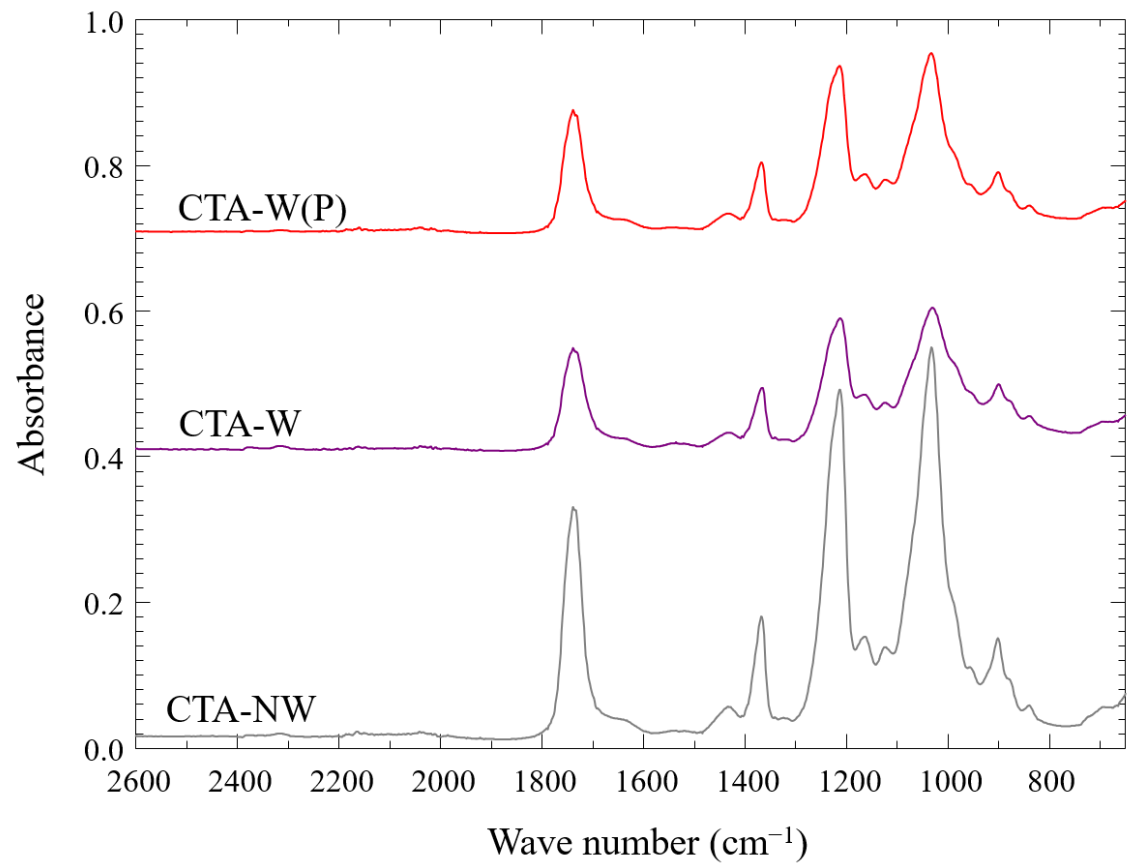

(b)

Figure 3. Fourier transform infrared spectroscopy (FTIR) spectra of (a) TFC, and (b) CTA-W(P), CTA-woven (W), and CTA-nonwoven (NW) membranes. 
Table 1. The chemical property, structural property, and intrinsic separation property of membranes.

\begin{tabular}{|c|c|c|c|c|c|}
\hline & Property & TFC & CTA-W(P) & CTA-W & CTA-NW \\
\hline & Membrane material & $\mathrm{PA} / \mathrm{PSf} / \mathrm{PET}$ & CTA/PET & CTA/PET & CTA/PET \\
\hline \multirow{3}{*}{ Structural property } & Thickness $(\mu \mathrm{m})$ & $105 \pm 4$ & $71 \pm 7^{a}$ & $\begin{array}{c}61 \pm 1^{a} \\
(44.7 \pm 14.1)^{b}\end{array}$ & $\begin{array}{c}129 \pm 6 \\
(144 \pm 24)^{b}\end{array}$ \\
\hline & Porosity (\%) & $66 \pm 1$ & $62 \pm 1$ & $\begin{array}{c}50 \pm 1 \\
(46 \pm 1)^{b}\end{array}$ & $\begin{array}{c}55 \pm 1 \\
(50 \pm 2)^{b}\end{array}$ \\
\hline & Structural parameter, $S(\mathrm{~mm})$ & $1.14 \pm 0.12$ & $0.73 \pm 0.31$ & $\begin{array}{c}0.82 \pm 0.39 \\
(1.00 \pm 0.54)^{b}\end{array}$ & $\begin{array}{c}1.77 \pm 0.20 \\
(1.38 \pm 0.26)^{b}\end{array}$ \\
\hline \multirow[b]{2}{*}{ Surface property } & Roughness, $R_{q}(\mathrm{~nm})$ & $69 \pm 15$ & $5 \pm 1$ & $5 \pm 1$ & $33 \pm 18$ \\
\hline & Contact angle $\left({ }^{\circ}\right)$ & $48 \pm 3$ & $63 \pm 1$ & $\begin{array}{c}67 \pm 2 \\
(73 \pm 2)^{b}\end{array}$ & $\begin{array}{c}63 \pm 4 \\
(64 \pm 2)^{b}\end{array}$ \\
\hline \multirow{9}{*}{ Mechanical property } & Young's modulus, E (MPa) & & & & \\
\hline & With tension in axial direction & $158 \pm 31$ & $427 \pm 34$ & $384 \pm 33$ & \multirow{2}{*}{$\begin{array}{c}261 \pm 70 \\
\text { (Isotropic) }\end{array}$} \\
\hline & With tension in diagonal direction & $38 \pm 3$ & $152 \pm 13$ & $264 \pm 14$ & \\
\hline & \multicolumn{2}{|l|}{ Tensile strain at break (\%) } & & & \\
\hline & With tension in axial direction & $67 \pm 2$ & $55 \pm 4$ & $65 \pm 7$ & \multirow{2}{*}{$\begin{array}{c}77 \pm 11 \\
\text { (Isotropic) }\end{array}$} \\
\hline & With tension in diagonal direction & $151 \pm 14$ & $175 \pm 16$ & $150 \pm 12$ & \\
\hline & \multicolumn{2}{|l|}{ Tensile stress at break (MPa) } & & & \\
\hline & With tension in axial direction & $54 \pm 3$ & $76 \pm 9$ & $92 \pm 8$ & \multirow{2}{*}{$\begin{array}{c}26 \pm 5 \\
\text { (Isotropic) }\end{array}$} \\
\hline & With tension in diagonal direction & $32 \pm 1$ & $76 \pm 2$ & $95 \pm 4$ & \\
\hline \multirow{7}{*}{ Intrinsic separation property } & Water permeability, $A\left(\mathrm{~L} /\left(\mathrm{m}^{2} \mathrm{~h}\right.\right.$ bar $\left.)\right)$ & $2.56 \pm 0.08$ & $1.06 \pm 0.07$ & $\begin{array}{c}0.41 \pm 0.01 \\
(0.33 \pm 0.04)^{b}\end{array}$ & $\begin{array}{c}0.53 \pm 0.03 \\
(0.46 \pm 0.07)^{b}\end{array}$ \\
\hline & $\mathrm{NaCl}$ rejection $(\%)$ & $96.5 \pm 0.9$ & $88.1 \pm 4.3$ & $\begin{array}{c}92.5 \pm 0.3 \\
(81.9)^{b, c}\end{array}$ & $\begin{array}{c}93.9 \pm 1.2 \\
(92.4)^{b, c}\end{array}$ \\
\hline & $\mathrm{NaCl}$ permeability, $B_{\mathrm{NaCl}}\left(\mathrm{L} /\left(\mathrm{m}^{2} \mathrm{~h}\right)\right)$ & $0.63 \pm 0.21$ & $0.67 \pm 0.24$ & $\begin{array}{c}0.15 \pm 0.01 \\
(0.14 \pm 0.03)^{b}\end{array}$ & $\begin{array}{c}0.16 \pm 0.04 \\
(0.10 \pm 0.01)^{b}\end{array}$ \\
\hline & $B_{\mathrm{NaCl}} / A($ bar $)$ & $0.25 \pm 0.08$ & $0.65 \pm 0.27$ & $\begin{array}{c}0.38 \pm 0.02 \\
(0.47 \pm 0.12)^{b}\end{array}$ & $\begin{array}{c}0.31 \pm 0.06 \\
(0.22 \pm 0.03)^{b}\end{array}$ \\
\hline & $\mathrm{Na}_{2} \mathrm{SO}_{4}$ rejection $(\%)$ & $98.9 \pm 0.2$ & $96.4 \pm 1.8$ & $99.0 \pm 0.04$ & $98.8 \pm 0.01$ \\
\hline & $\mathrm{Na}_{2} \mathrm{SO}_{4}$ permeability, $B_{\mathrm{Na} 2 \mathrm{SO} 4}\left(\mathrm{~L} /\left(\mathrm{m}^{2} \mathrm{~h}\right)\right)$ & $0.13 \pm 0.02$ & $0.17 \pm 0.08$ & $0.019 \pm 0.0002$ & $0.029 \pm 0.001$ \\
\hline & $B_{\mathrm{Na} 2 \mathrm{SO} 4} / A$ (bar) & $0.053 \pm 0.008$ & $0.17 \pm 0.09$ & $0.047 \pm 0.001$ & $0.055 \pm 0.001$ \\
\hline
\end{tabular}

a The cross-sections of CTA-W(P) and CTA-W were non-uniform due to the embedded mesh. Thickness at the thinnest parts were $52 \pm 7 \mu \mathrm{m}$ and $25 \pm 1 \mu \mathrm{m}$ for CTA-W(P) and CTA-W, respectively. ${ }^{\mathrm{b}}$ Values in parentheses were reported in previous study [24]. The values in current study were slightly different, likely due to variations of different membrane batches. ${ }^{c}$ Salt rejection was tested at 3.75 bar, using $20 \mathrm{mM} \mathrm{NaCl}$ as feed in previous study [24].

\subsection{Intrinsic Separation Property of Membranes}

Water and salt permeabilities of membranes are shown in Table 1. The studied membranes had moderate to high rejections to $\mathrm{NaCl}$ and $\mathrm{Na}_{2} \mathrm{SO}_{4}$. CTA-W(P) had a water permeability of $1.06 \mathrm{~L} /\left(\mathrm{m}^{2} \mathrm{~h}\right.$ bar $\left.)\right)$, while lower water permeability of $0.41 \mathrm{~L} /\left(\mathrm{m}^{2} \mathrm{~h}\right.$ bar $)$ and $0.53 \mathrm{~L} /\left(\mathrm{m}^{2} \mathrm{~h}\right.$ bar) were shown by CTA-W and CTA-NW, respectively. Compared to $C T A-W(P)$, the dense structure of CTA-W was likely responsible for the increased hydraulic resistance. The low permeability of CTA-NW was mainly contributed by its thicker structure. Trade-off between membrane permeability and selectivity can be seen for the CTA membranes. Higher $A$ value of CTA-W(P) was accompanied with a higher $B / A$ value compared to CTA-W and CTA-NW. To overcome the limitation of CTA membrane, other types of membranes were also developed for OM process. Table A1 in Appendix C lists the intrinsic separation property of several commercial FO membranes reported. Most of these membranes were TFC membranes. Compared to the integral asymmetric CTA membranes, these TFC membranes had higher $A$ values and smaller $B / A$ values. As shown in Table $1, A$ value of TFC was $2.56 \mathrm{~L} /\left(\mathrm{m}^{2} \mathrm{~h}\right.$ bar), which was two times higher than that of CTA-W $(\mathrm{P})$. The improvement could be attributed to the thinner and more hydrophilic 
polyamide layer (Table 1). Superior combination of water permeability and selectivity was also exhibited by TFC. $B_{\mathrm{NaCl}} / A$ and $B_{\mathrm{Na} 2 \mathrm{SO} 4} / A$ of TFC were 0.25 bar and 0.053 bar, respectively, both lower than those of CTA-W(P). As the salt flux/water flux $\left(J_{s} / J_{v}\right)$ ratio is proportional to $B / A$ value of membrane in OM process, the solute reverse diffusion of TFC would be less severe. Nevertheless, OM water flux does not linearly increase with membrane permeability and it also depends on the support layer. In this work, CTA-W(P) was used as a benchmark to comprehensively evaluate the influence of membrane property on OM performance.

\subsection{Membrane Performance in Osmotically-Driven Processes \\ 3.3.1. FO Performance of Membranes}

The FO performance of TFC, CTA-W(P), CTA-W and CTA-NW were evaluated using $0.5 \mathrm{M} \mathrm{NaCl}$ DS and $10 \mathrm{mM} \mathrm{NaCl}$ FS. In AL-DS mode, TFC had the highest $J_{v}$ and small $J_{s} / J_{v}$ (Figure A3a,b in Appendix D). For the integral asymmetric CTA membranes, CTA-W and CTA-NW had relatively low $J_{v}$ that was approximately half of $J_{v} C T A-W(P)$. It was mainly attributed to the low $A$ values of CTA-W and CTA-NW, which were only half of $A_{C T A-W(P)}$. CTA-W(P) also exhibited higher $J_{v}$ than CTA-W and CTA-NW when $2 \mathrm{M} \mathrm{NaCl}$ DS was used, in both AL-DS and AL-FS modes (Figure A3a,c). All the three CTA membranes in this study had moderate $J_{S} / J_{v}(<1 \mathrm{~g} / \mathrm{L})$ (Figure A3b,d). In general, CTA-W(P) was more promising for OM applications than the other two CTA membranes due to its higher $A$ value, smaller $S$ value and moderate $B$ value. Thus, CTA-W(P) was used for further OM study in this work.

As discussed in the above, TFC exhibited higher $J_{v}$ than CTA-W(P) in AL-DS mode when $0.5 \mathrm{M} \mathrm{NaCl}$ DS and $10 \mathrm{mM} \mathrm{NaCl} \mathrm{FS}$ were used. However, when a more concentrated DS of $2 \mathrm{M} \mathrm{NaCl}$ was used, $J_{v} C T A-W(P)$ was about $30 \%$ higher than $J_{v}$ TFC in both AL-DS and AL-FS modes (Figure 4). In OM processes, $J_{v}$ is mainly governed by membrane frictional resistance loss, ICP, and solute reverse diffusion. Due to the low $J_{S} / J_{v}$ of TFC and CTA-W(P), membrane frictional resistance loss and ICP played more important roles on $J_{v}$. ICP was less severe when FS and DS concentrations were low, leading to a greater importance of $A$ value for $J_{v}$. Under such frictional-resistance-dominated conditions, the more permeable TFC achieved higher $J_{v}$. When a more concentrated DS was used, however, ICP governed $J_{v}$ and CTA-W(P) with smaller $S$ value performed better.

To further elucidate the governing mechanisms, forward osmosis (FO) tests with different FS and DS concentrations were conducted on TFC and CTA-W(P). $J_{v}$ of TFC and CTA$\mathrm{W}(\mathrm{P})$ are compared in Figure 4. With a DI water FS and a low-concentration DS of $0.2 \mathrm{M}$ $\mathrm{NaCl}$ (AL-DS), ICP was less severe, represented by a high FO efficiency of 0.70 for CTA$\mathrm{W}(\mathrm{P})$. TFC achieved significantly higher $J_{v}$ than that of CTA-W(P) $\left(J_{v} T F C / J_{v} C T A-W(P)=1.82\right.$, Figure $4 \mathrm{a}) . J_{v T F C} / J_{v} C T A-W(P)$ ratio was reduced as the concentrations of FS and DS increased. $J_{v} C T A-W(P)$ was higher than $J_{v}$ TFC when $2 \mathrm{M} \mathrm{NaCl}$ DS was used, especially when a concentrated FS of $0.5 \mathrm{M} \mathrm{NaCl}$ was used $\left(J_{v T F C} / J_{v C T A-W(P)}=0.55\right.$, AL-DS). This was attributed to the remarkably enhanced influence of ICP in this scenario, represented by a lower FO efficiency of 0.18 for CTA-W(P). In AL-FS mode, $J_{v} T_{F C} / J_{v} C T A-W(P)$ was 1.18 using $0.2 \mathrm{M}$ $\mathrm{NaCl}$ DS and DI water FS (Figure $4 \mathrm{~b}$ ), which was significantly lower than $J_{v} T F C / J_{v} C T A-W(P)$ in AL-DS mode. A low FO efficiency of 0.56 for CTA-W(P) implicated the more severe influence of dilutive ICP (AL-FS) than concentrative ICP (AL-DS) when identical FS and DS were used. Therefore, in AL-FS mode, more osmotic driving force was lost for TFC with larger $S$ value. It can be seen from the above results that assessment of membranes in OM process should be based on membrane property and operational condition. Membranes with higher $J_{v}$ in one condition may show inferior $J_{v}$ in another condition. In view of the non-linear dependence of OM performance on membrane properties and the trade-off of these properties, their combined influences in different conditions will be further discussed. 


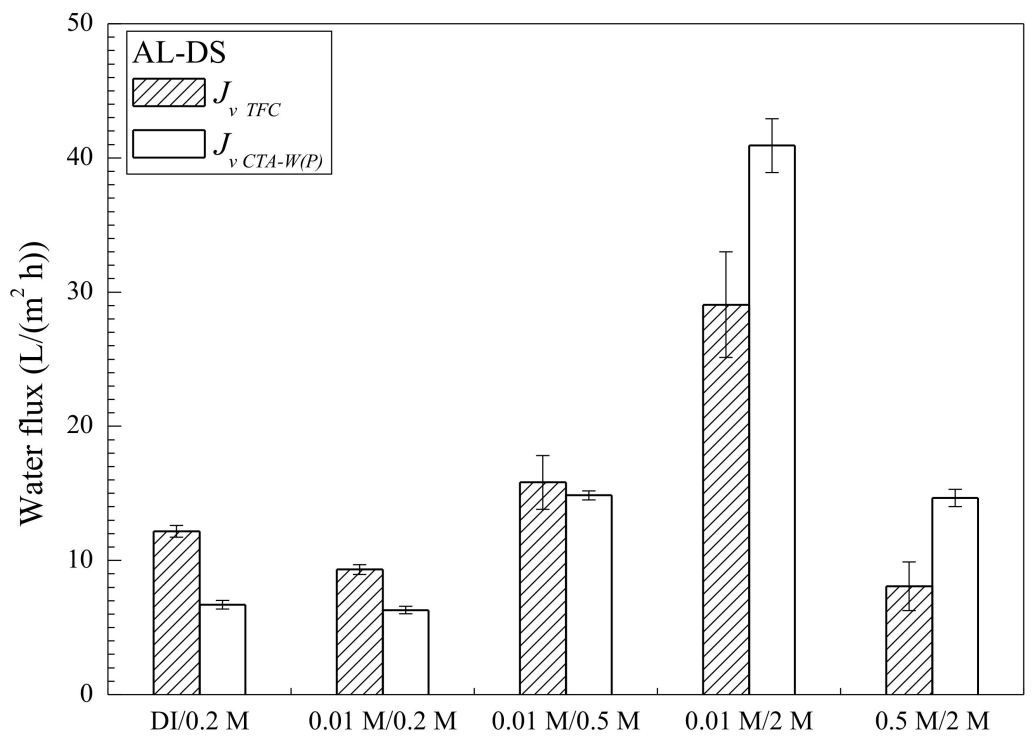

Feed solution/draw solution

(a)

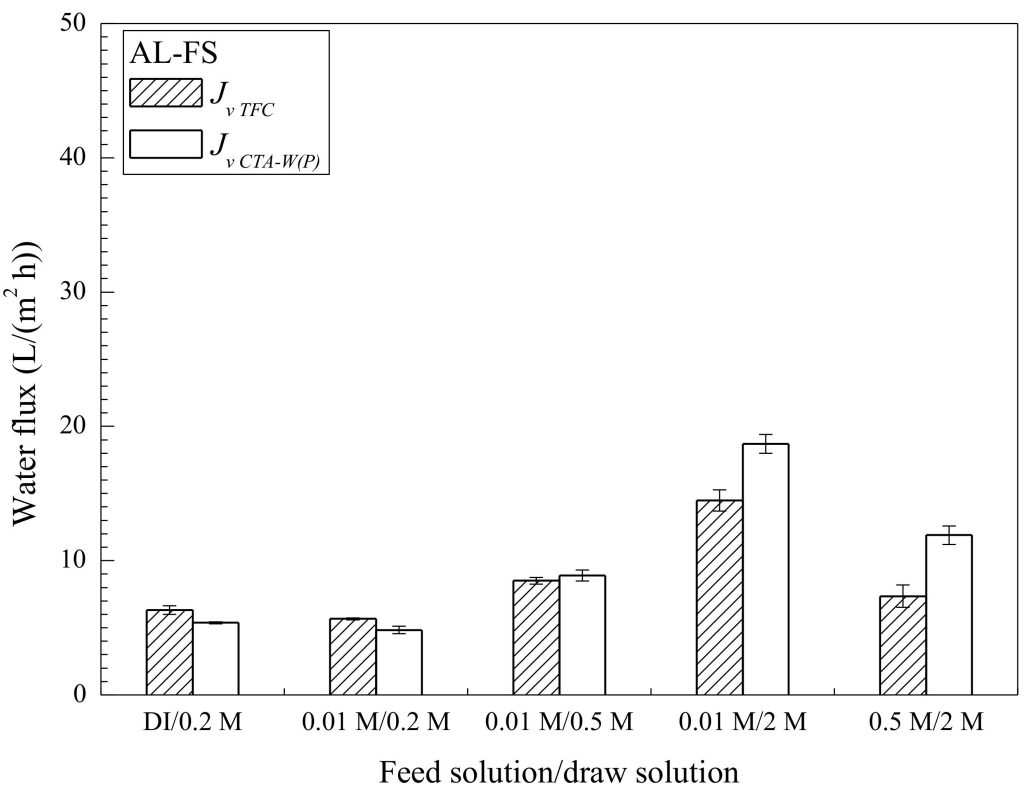

(b)

Figure 4. Forward osmosis (FO) water flux of TFC and CTA-W(P) membranes with different feed and draw solutions. The tests were performed in (a) AL-DS mode, and (b) AL-FS mode. Pure water, $10 \mathrm{mM}$ and $0.5 \mathrm{M} \mathrm{NaCl}$ were used as feed solution (FS), which are denoted as DI, $0.01 \mathrm{M}$ and $0.5 \mathrm{M} .0 .2 \mathrm{M}$, $0.5 \mathrm{M}$, and $2 \mathrm{M} \mathrm{NaCl}$ were used as draw solution (DS), which are denoted as $0.2 \mathrm{M}, 0.5 \mathrm{M}$, and $2 \mathrm{M}$.

\subsubsection{Anti-Scaling Performance of Membranes}

OM applications can use different types of saline water, which may contain sparingly soluble ions and impurities with high concentrations. For example, in desalination-hybrid processes where seawater or seawater desalination brine is used, a great amount of scaling precursors like $\mathrm{Ca}^{2+}, \mathrm{Mg}^{2+}, \mathrm{SO}_{4}{ }^{2-}$, and $\mathrm{CO}_{3}{ }^{2-}$ exist [54]. Sparingly soluble salts may precipitate and deposit on membrane during operation. In this study, $\mathrm{FS}$ containing $\mathrm{Ca}^{2+}$ and $\mathrm{SO}_{4}{ }^{2-}$ were used to investigate the impact of scaling on TFC and CTA-W(P). The membranes were tested in AL-FS mode with mitigated internal scaling [50]. Water flux of TFC and CTA-W(P) in the scaling tests are shown in Figure 5. CTA-W(P) exhibited stable 
performance during the scaling test of $18 \mathrm{~h}$, without significant variation of $J_{v}$ compared to the baseline. In contrast, $J_{v}$ of TFC drastically declined after $3 \mathrm{~h}$ of scaling test. Severe leakage of draw solutes into FS took place after test of $5 \mathrm{~h}$ and resulted in the interruption of operation. Damage at the polyamide layer was observed when the tested membrane was later examined under FESEM (Figure S2). In the scaling test, $\mathrm{Ca}^{2+}$ and $\mathrm{SO}_{4}{ }^{2-}$ in FS were concentrated and caused precipitation of gypsum crystals. According to the FESEM and AFM images of membrane rejection layer (Figure 2), TFC had a rougher surface (roughness $\left.R_{q}=69 \mathrm{~nm}\right)$ than that of CTA-W $(\mathrm{P})\left(R_{q}=5 \mathrm{~nm}\right)($ Table 1$)$. Moreover, the carboxylic groups of polyamide layer provided binding site for $\mathrm{Ca}^{2+}$ and led to surface crystallization of gypsum [55]. Therefore, faster deposition and growth of gypsum crystals were prone to take place on TFC. Crystallization beneath feed spacer filaments could also cause damage to membrane rejection layer, which tended to be more severe for the TFC membrane due to its thinner rejection layer [51]. Thus, CTA-W(P) had advantage in this condition because of its surface morphology, chemical property, and structure.

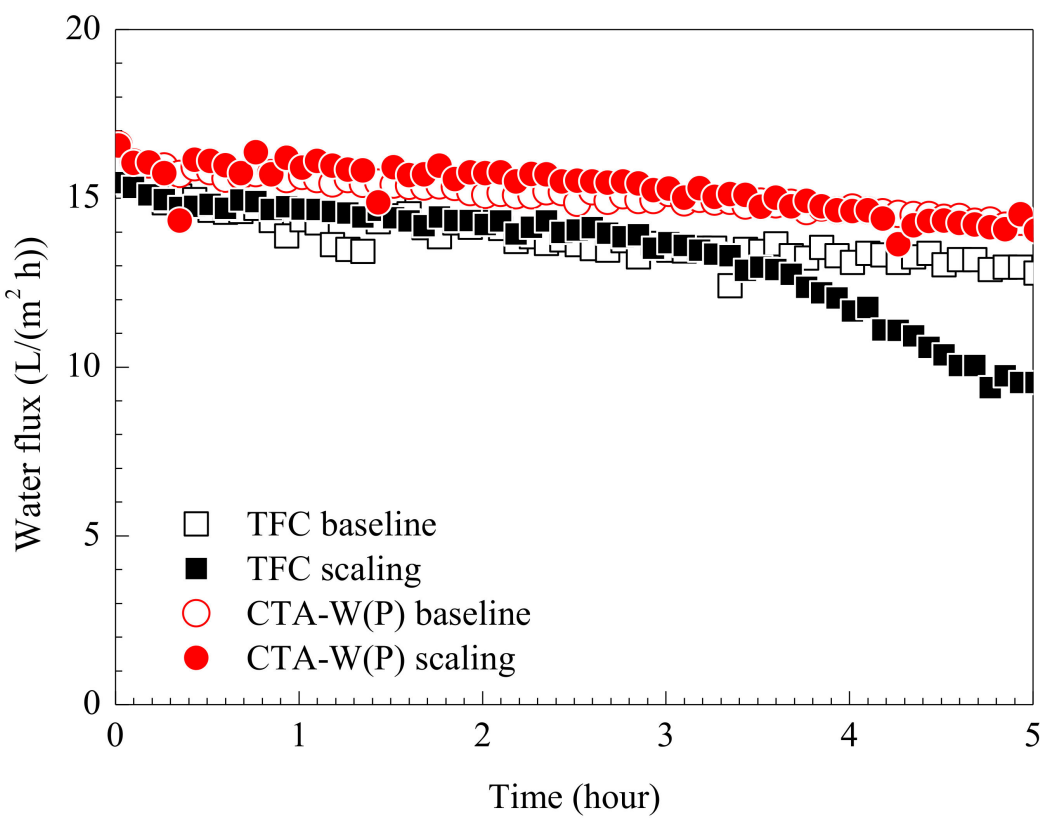

Figure 5. Water flux of TFC and CTA-W(P) in FO scaling tests. Testing conditions: FS for baseline tests was $0.163 \mathrm{M} \mathrm{NaCl}$; FS for scaling tests was a mixed solution containing $72 \mathrm{mM} \mathrm{Na}_{2} \mathrm{SO}_{4}, 26.1 \mathrm{mM}$ $\mathrm{CaCl}_{2}$, and $10 \mathrm{mM} \mathrm{NaCl}$; crossflow velocities of $\mathrm{FS}$ and DS on membrane were $23.2 \mathrm{~cm} / \mathrm{s} ; 2-3 \mathrm{M}$ $\mathrm{NaCl}$ were used as DS to achieve initial water flux of $15 \pm 1 \mathrm{~L} /\left(\mathrm{m}^{2} \mathrm{~h}\right)$.

\subsubsection{PRO Performance of Membranes}

TFC and CTA-W(P) were tested in PRO process to estimate their efficiency of osmotic power production. Both membranes can withstand transmembrane pressure of $0-22$ bar without burst. As $\Delta P$ gradually increased, water permeation through membrane was retarded. $J_{v}$ of TFC declines less than that of CTA-W $(\mathrm{P})$ upon pressurization (Figure 6a). TFC achieved a peak power density of $8.4 \mathrm{~W} / \mathrm{m}^{2}$ at $\Delta P$ of 20 bar (Figure $6 \mathrm{~b}$ ). The peak power density of CTA-W(P) was $4.8 \mathrm{~W} / \mathrm{m}^{2}$ at $\Delta P$ of 13 bar. In PRO process, the theoretically maximum power density can be achieved at $\Delta P=1 / 2 \Delta \pi$, which was 22 bar in the current testing condition (10 $\mathrm{mM} \mathrm{NaCl} \mathrm{FS}$ and $1 \mathrm{M} \mathrm{NaCl}$ DS). As in Figure $6 \mathrm{c}, J_{s} / J_{v}$ of CTA-W(P) sharply increased at $\Delta P>10$ bar. CTA-W $(\mathrm{P})$ had relatively lower intrinsic salt rejection than TFC. Prior studies revealed that osmotic membranes are prone to rejection deterioration at high applied pressure due to the stretching of membranes [56]. CTA membrane with linear polymer network became loose after deformed and caused severe salt leakage. Therefore, the peak power density of CTA-W(P) was reached at a $\Delta P$ much lower than 
the theoretically optimal value. In contrast, TFC with superior salt rejection and a more rigid cross-linked polyamide rejection layer can minimize the influence of solute reverse diffusion and showed higher PRO performance.

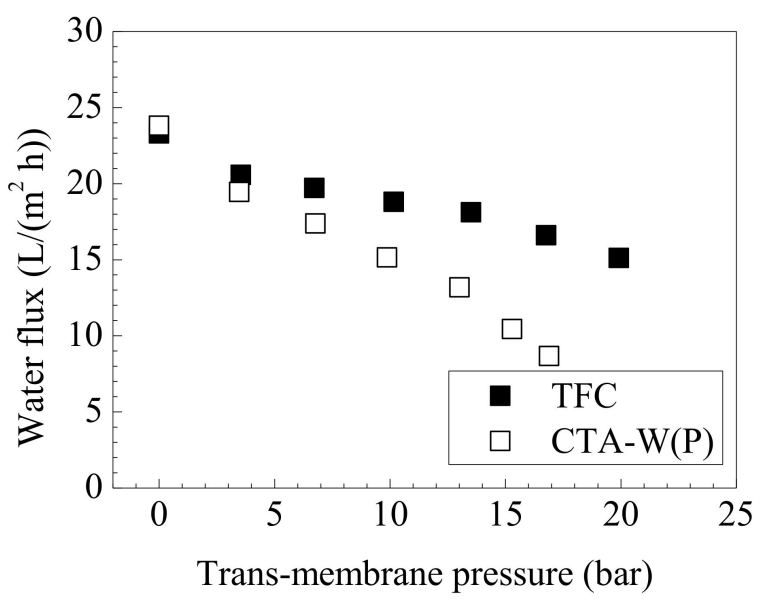

(a)

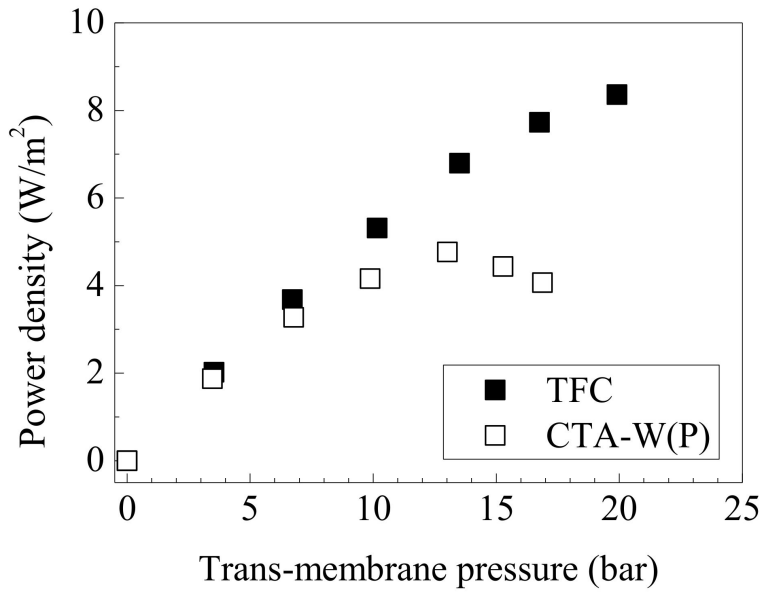

(b)

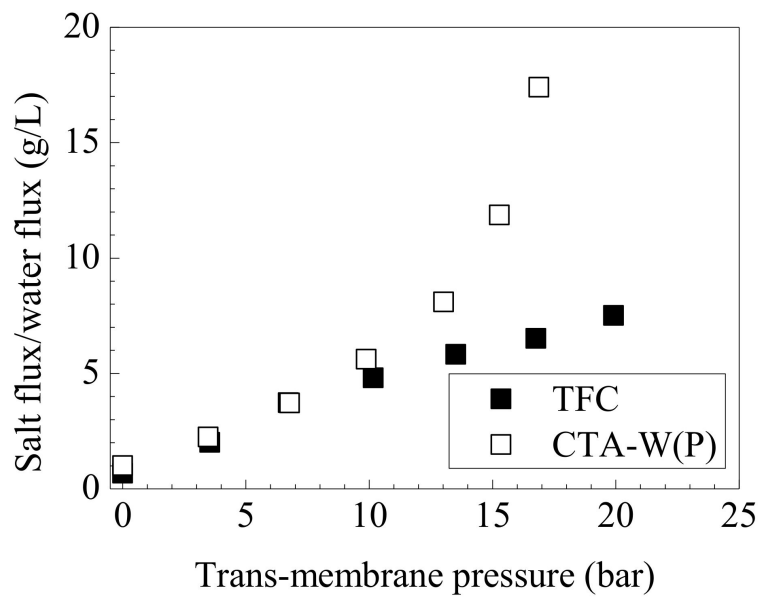

(c)

Figure 6. Pressure-retarded osmosis (PRO) performance of TFC and CTA-W(P) membranes: (a) water flux, (b) power density, and (c) salt flux/water flux ratio. Testing conditions: $10 \mathrm{mM} \mathrm{NaCl}$ as $\mathrm{FS}, 1 \mathrm{M}$ $\mathrm{NaCl}$ as DS, and active-layer-facing-draw-solution (AL-DS) mode. 


\section{Implications}

The study of TFC and CTA-W(P) showed the non-linear dependence of OM water flux on membrane property. It was complicated with the trade-off of critical membrane properties, e.g., $A, B / A, S$, and mechanical strength, and increased the complexity of membrane optimization. FO membranes in the literature were investigated to study the comprehensive influence of membrane permeability and structure on $J_{v}$. Experimental data of the membranes in the current work and the literature (Table A1, Tables S1 and S2) were plotted according to two potential applications: (1) dehydration of low salinity solutions using seawater as DS (Figure 7a,b), and (2) seawater desalination using high concentration DS (Figure $7 \mathrm{c}, \mathrm{d}$ ). As $J_{v}$ is positively related to both $A$ and $K_{m}, K_{m}$ was plotted instead of $S$ for better illustration and understanding. The isolines present datapoints with the same $J_{v}$, which were achieved by membranes with different $A$ and $K_{m}$. Higher $J_{v}$ were mostly exhibited by membranes with higher $A$ and $K_{m}$, if the solute reverse diffusion was low. Meanwhile, there would be a governing factor in a specific case, depending on the combination of $A$ and $K_{m}$. For example, when $K_{m}$ was smaller than $20 \mathrm{~L} /\left(\mathrm{m}^{2} \mathrm{~h}\right.$ ) (i.e., $\mathrm{S}>0.3 \mathrm{~mm}$ ), the increase of $J_{v}$ with $K_{m}$ was more remarkable while increasing $A$ had less effect on $J_{v}$ if the membranes had moderate $A$ value. It means that improving membrane structure can significantly improve $J_{v}$. On the other hand, for membranes with optimized structure (e.g., $K_{m}>20 \mathrm{~L} /\left(\mathrm{m}^{2} \mathrm{~h}\right)$ ) but low water permeability (e.g., $\mathrm{A}<2 \mathrm{~L} /\left(\mathrm{m}^{2} \mathrm{~h}\right.$ bar)), the increase of $J_{v}$ with $A$ was more significant, suggesting that $A$ was the governing factor on $J_{v}$. The membrane property dominating OM performance also varied by testing condition. Taking CTA-W $(\mathrm{P})\left(A=1.06 \mathrm{~L} /\left(\mathrm{m}^{2} \mathrm{~h}\right.\right.$ bar $\left.), K_{m}=7.9 \mathrm{~L} /\left(\mathrm{m}^{2} \mathrm{~h}\right)\right)$ as an example, the constraint of its low water permeability on $J_{v}$ was crucial in the test with low concentration FS and AL-DS mode (Figure 7a). As this condition was frictional-resistance-dominated, improving the $A$ value of CTA-W(P) can effectively increase $J_{v}$. In contrast, the constraint of $K_{m}$ on $J_{v}$ became more important when seawater was used as FS (Figure $7 \mathrm{c}, \mathrm{d}$ ), i.e., $J_{v}$ varied more obviously with $K_{m}$ instead of $A$ value, due to the dominant effect of ICP. Comparison of the above membranes showed that the dominant factor and mechanism for OM flux varied by membrane property and OM conditions.

A framework was proposed to illustrate the mechanisms dominating flux performance, and to guide the optimization of membranes for targeted OM applications. A few potential modes of OM applications have been studied in Section 3.3. The FO efficiency $\left(J_{v} / J_{v}\right.$ Theo $)$ of $\mathrm{CTA}-\mathrm{W}(\mathrm{P})$ varied with the FS, DS, and membrane orientation due to the comprehensive influence of concentration polarization, frictional resistance loss and solute reverse diffusion (Figure 8). With CTA-W(P) as a benchmark, pros and cons of TFC were assessed using this framework (Figure 8). When $10 \mathrm{mM} \mathrm{NaCl} \mathrm{FS}$ and $0.5 \mathrm{M} \mathrm{NaCl}$ DS were used, moderate FO efficiency around 0.5 was showed by CTA-W(P). Both ICP and frictional resistance loss constrained the performance of CTA-W(P). TFC had comparable $J_{v}$ as CTA-W(P) under this condition, and using TFC as an alternative might not significantly enhance $J_{v}$, but its excellent salt rejection would be beneficial to reduce the solute reverse diffusion. Higher FO efficiency is shown at the right side of the diagram. The corresponding OM conditions (e.g., tests with AL-DS mode, dilute FS and DS) had less ICP, and $J_{v}$ was likely to be governed by frictional resistance loss mechanism. $J_{v}$ TFC $/ J_{v} C T A-W(P)$ sharply increased in the conditions with high FO efficiency. In an ideal case without ICP (FO efficiency $=1), J_{v}$ will be linearly proportional to $A$. In Figure $8, J_{v}{ }_{T F C} / J_{v} C T A-W(P)$ tended to approximate $A_{T F C} / A_{C T A-W(P)}$ at the right side of the diagram. For applications with less ICP, indicated by high FO efficiency, the influence of frictional resistance loss is critical. $J_{v}$ can be significantly increased by using membranes with higher $A$ value (e.g., TFC). 


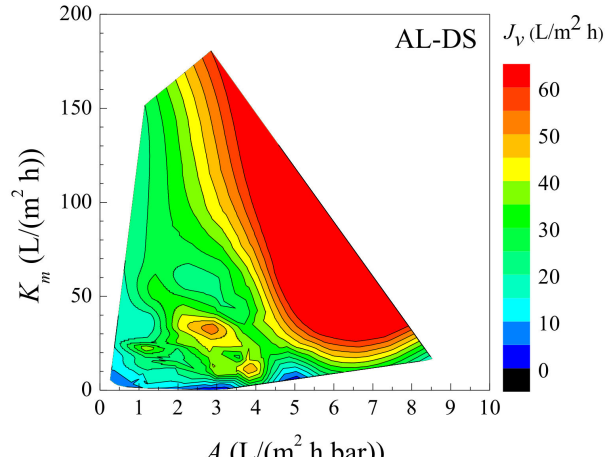

(a)

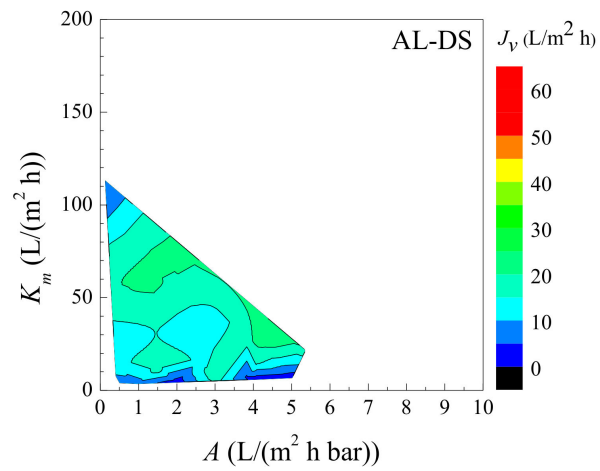

(c)

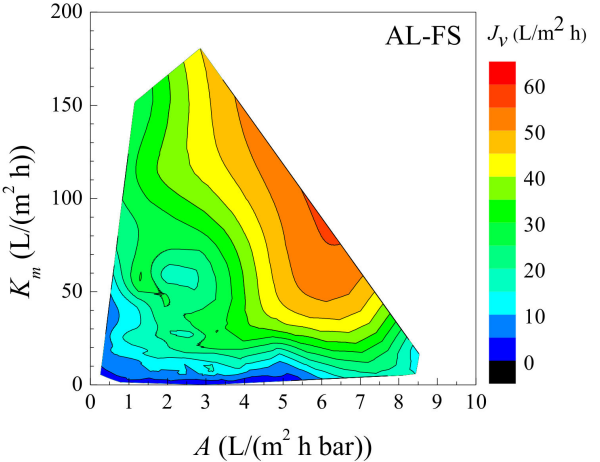

(b)

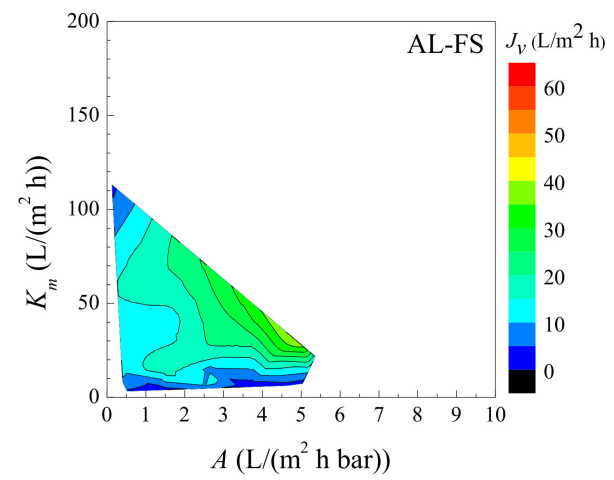

(d)

Figure 7. FO water flux of membranes with different water permeability $(A)$ and mass diffusion coefficient $\left(K_{m}\right)$. The data was obtained from the experiments in the current work and the literature, and the membrane properties are presented in Table A1 and Table S1. Data in $(\mathbf{a}, \mathbf{b})$ were evaluated with FS of 0-10 mM NaCl and DS of 0.5-0.75 M NaCl. Data in (c,d) were evaluated with FS of $0.5-0.6 \mathrm{M} \mathrm{NaCl}$ and DS of $1.5-2 \mathrm{M} \mathrm{NaCl}$.

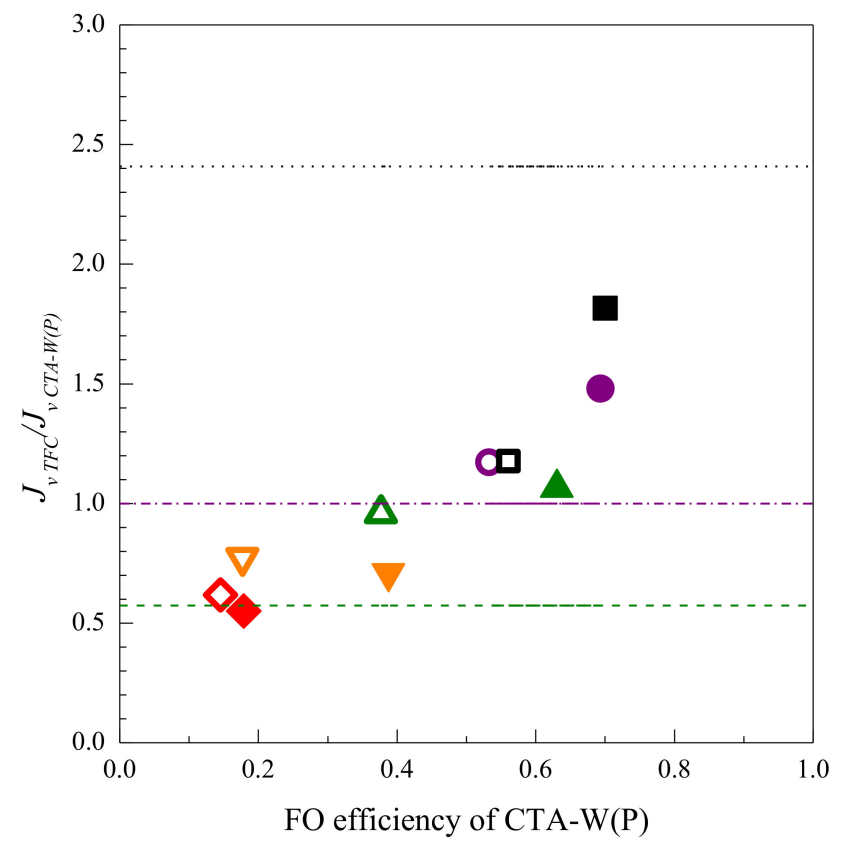
$0.5 \mathrm{M} / 2 \mathrm{M}, \mathrm{AL}-\mathrm{FS}$
$0.5 \mathrm{M} / 2 \mathrm{M}, \mathrm{AL}-\mathrm{DS}$
$\nabla \quad 0.01 \mathrm{M} / 2 \mathrm{M}$, AL-FS
$\nabla 0.01 \mathrm{M} / 2 \mathrm{M}, \mathrm{AL}-\mathrm{DS}$
$\Delta \quad 0.01 \mathrm{M} / 0.5 \mathrm{M}$, AL-FS
- $0.01 \mathrm{M} / 0.5 \mathrm{M}, \mathrm{AL}-\mathrm{DS}$
- $0.01 \mathrm{M} / 0.2 \mathrm{M}, \mathrm{AL}-\mathrm{FS}$
$0.01 \mathrm{M} / 0.2 \mathrm{M}, \mathrm{AL}-\mathrm{DS}$
口 DI/0.2 M, AL-FS
DI/0.2 M, AL-DS $A_{T F C} / A_{C T A-W(P)}$
$\cdots \cdot \cdots J_{v T F C} / J_{v C T A-W(P)}=1$
- - - $K_{m T F C} / K_{m C T A-W(P)}$

Figure 8. The FO efficiency of benchmark membrane (CTA-W(P)) and $J_{v} T F C / J_{v} C T A-W(P)$ in different testing conditions. DI water, $0.01 \mathrm{M}$ and $0.5 \mathrm{M} \mathrm{NaCl}$ were used as FS; 0.2 M, 0.5 M, and $2 \mathrm{M} \mathrm{NaCl}$ were used as DS, as in the legend. 
Lower FO efficiency is shown at the left side of the diagram (Figure 8). Results of tests with high ICP potential, e.g., tests with AL-FS mode, concentrated FS or DS, are mostly in this area. TFC exhibited lower $J_{v}$ than $J_{v} C T A-W(P)$ here despite of the high $A_{T F C}$, and $K_{m}$ was the governing factor. In harsh condition like FO desalination with seawater as FS and high concentration DS, Equations (4) and (5) can be derived as $J_{v}=K_{m} \ln \left(\pi_{\text {draw }} / \pi_{\text {feed }}\right)$ [49]. $J_{v}$ will be almost linearly proportional to $K_{m}$ as $\pi_{\text {draw }} / \pi_{\text {feed }}$ is constant. The performance of TFC and CTA-W(P) with $0.5 \mathrm{M} \mathrm{FS}$ and $2 \mathrm{M}$ DS agreed with this equation. $J_{v}$ TFC $/ J_{v} C T A-W(P)$ tended to approximate $K_{m}$ TFC $/ K_{m} C T A-W(P)$ in both AL-DS and AL-FS modes (Figure 8). Increasing $A$ value of membrane would have minor effect on $J_{v}$ but might compromise the membrane selectivity. Therefore, in applications dominated by ICP, indicated by low FO efficiency of the benchmark membrane, optimization or selection of membrane should be targeted to have improved mass transfer coefficient. Moreover, active layer with higher salt rejection, and lower fouling propensity for systems with high saturation index, would be important to reduce the salt leakage and $J_{s}$-induced ICP.

\section{Conclusions}

In this work, the influence of membrane permeability and structure on OM performance was studied by systematically characterizing and evaluating the OM performance of commercial osmotic membranes. The polyamide-based TFC membrane with superior water permeability and salt rejection had high water flux in the FO conditions with low ICP, as well as in PRO tests with high hydraulic pressure. In FO tests with more severe ICP, however, an integral asymmetric CTA membrane $(\mathrm{CTA}-\mathrm{W}(\mathrm{P}))$ with optimized structure of support layer showed higher water flux, despite of its lower water permeability coefficient. In OM process, flux is highly non-linear with respect to membrane property. The trade-off of membrane properties imposes limitations on membrane optimization. This study established a framework based on the FO efficiency to identify the factors governing water flux in different conditions. High FO efficiency indicates the dominant effect of frictional resistance loss, and improvement of the membrane water permeability would be more effective to achieve higher water flux. On the other hand, low FO efficiency is usually exhibited in the ICP-dominated condition, and membranes with smaller structural parameter should be used to enhance OM performance.

Supplementary Materials: The following are available online at https:/ / www.mdpi.com/2077-0 375/11/2/153/s1, S1. Setup for Membrane Permeability Measurement, S2. Surface Morphology of TFC Membrane after Scaling Test, S3. Property and Performance of Lab-Scale FO Membranes in the Literature.

Author Contributions: Conceptualization, J.W. and Q.S.; Methodology, J.W.; Investigation, J.W., Q.S. and X.L.; Writing-Original Draft Preparation, J.W.; Writing—Review \& Editing, J.W., Q.S. and X.L.; Supervision, Q.S. All authors have read and agreed to the published version of the manuscript.

Funding: This research was funded by Singapore National Research Foundation under its Environment and Water Industry Program Office (EWI) (1102-IRIS-07-01), National Natural Science Foundation of China (51808264), Collaborative Innovation Center of Water Treatment Technology \& Material (XTCXSZ2020-4) and Senior Talent Funding of Jiangsu University (18JDG031).

Institutional Review Board Statement: Not applicable.

Informed Consent Statement: Not applicable.

Conflicts of Interest: The authors declare no conflict of interest.

\section{Appendix A. Structure of CTA-W and CTA-NW Membranes}

Cross-sections of CTA-W and CTA-NW are shown in Figure A1. CTA-W had a similar structure as CTA-W(P), consisting of a CTA rejection layer and a mesh embedded in the CTA layer. Compared to CTA-W(P), the CTA layer of CTA-W was thinner and denser without macrovoid, which resulted in a slightly larger $S$ value of $0.82 \mathrm{~mm}$. CTA-NW comprised a CTA layer and a nonwoven fabric (thickness of $\sim 80 \mu \mathrm{m}$ ) supported on the 
bottom. Finger-like pore structure was shown in the CTA layer. Due to the thick and dense nonwoven fabric support, CTA-NW had a smaller porosity of $55 \%$ and thicker cross-section $(129 \mathrm{~mm})$ than CTA-W $(\mathrm{P})$, as well as had a large $S$ value of $1.77 \mathrm{~mm}$.

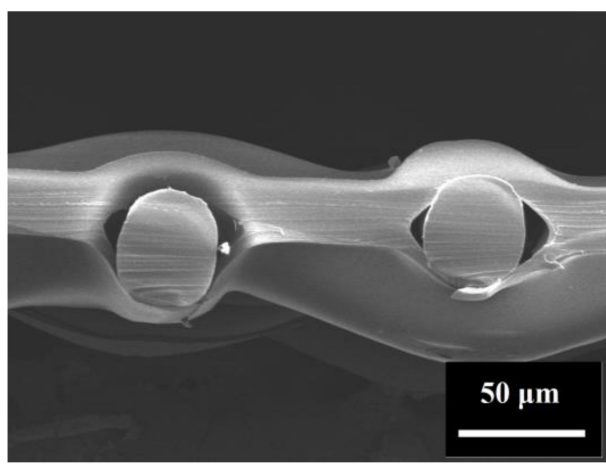

(a)

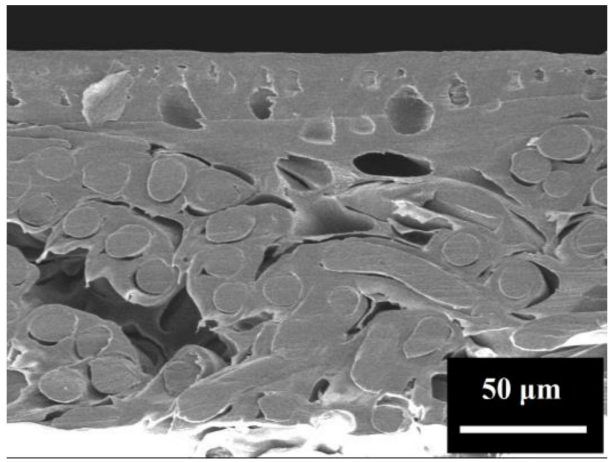

(b)

Figure A1. FESEM micrographs of the cross-sections (at 500×) of (a) CTA-W and (b) CTA-NW.

\section{Appendix B. Tensile Strength Tests}

Mechanical property of the mesh-reinforced TFC, CTA-W(P), and CTA-W membranes was measured with tension in the axial direction along filaments, and the diagonal direction of mesh opening, as shown in Figure A2.

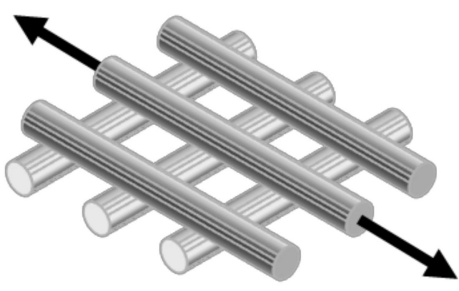

(a)

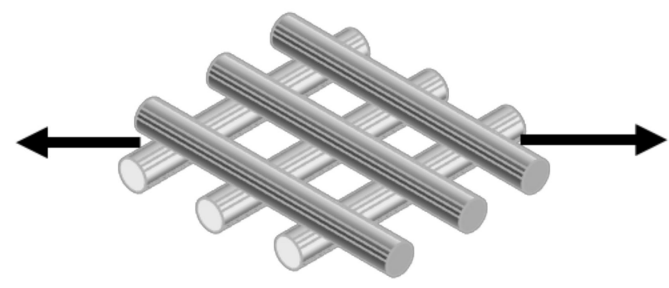

(b)

Figure A2. Illustration of tensile testing with tension in (a) axial direction and (b) diagonal direction.

\section{Appendix C. Property and Performance of Commercial FO Membranes}

The separation property and FO performance of membranes in this study was compared with other commercial FO membranes reported in the literature. TFC membranes generally showed higher water permeability and selectivity than integral asymmetric membranes (Table A1). With support layer tailored to have small structural parameter, the TFC membranes achieved high water flux in OM process. 
Table A1. Property and FO performance of commercial membranes.

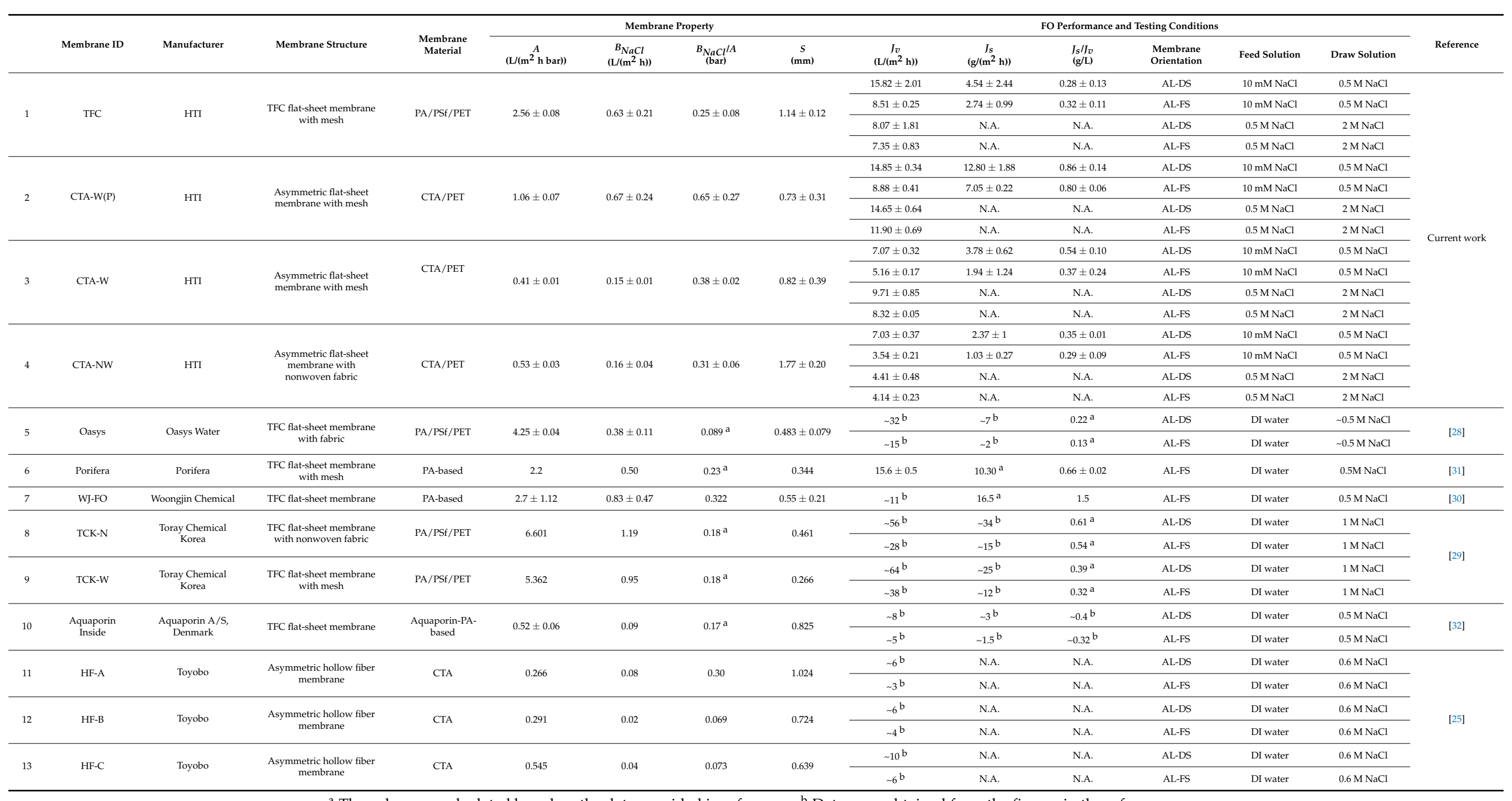

${ }^{a}$ The value was calculated based on the data provided in references. ${ }^{b}$ Data were obtained from the figures in the references. 


\section{Appendix D. FO Performance of Membranes}

FO performance of the membranes were tested with DS of $0.5 \mathrm{M}$ and $2 \mathrm{M} \mathrm{NaCl}$, and $\mathrm{FS}$ of $10 \mathrm{mM} \mathrm{NaCl}$ (Figure A3). Comparable $J_{v}$ were shown by TFC and CTA-W(P) with $0.5 \mathrm{M} \mathrm{NaCl}$ DS. TFC had remarkably lower $J_{s} / J_{v}$ due to the superior salt rejection of polyamide rejection layer. Nevertheless, TFC had lower $J_{v}$ than CTA-W(P) when 2 M DS was used. Due to the constraint of low $A$ values, CTA-W and CTA-NW had low $J_{v}$ in the tests. CTA-NW with large $S$ value encountered more severe ICP and showed the lowest $J_{v}$ of all the membranes.

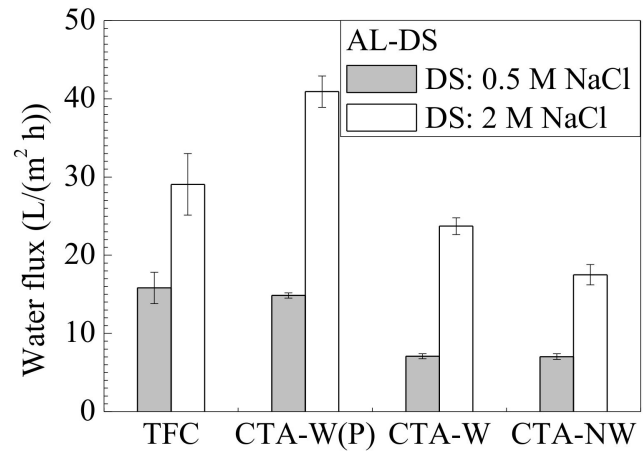

(a)

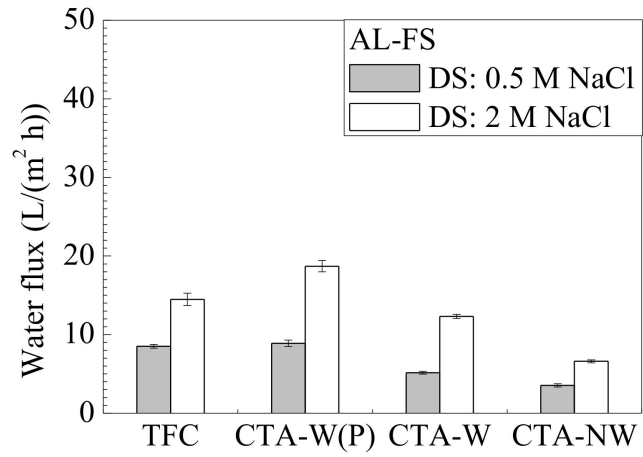

(c)

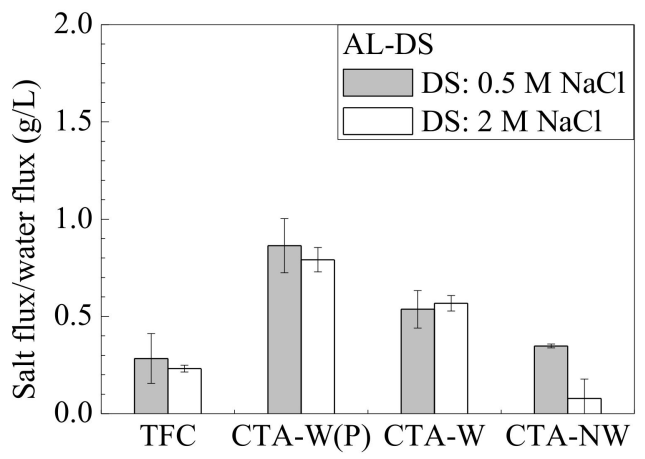

(b)

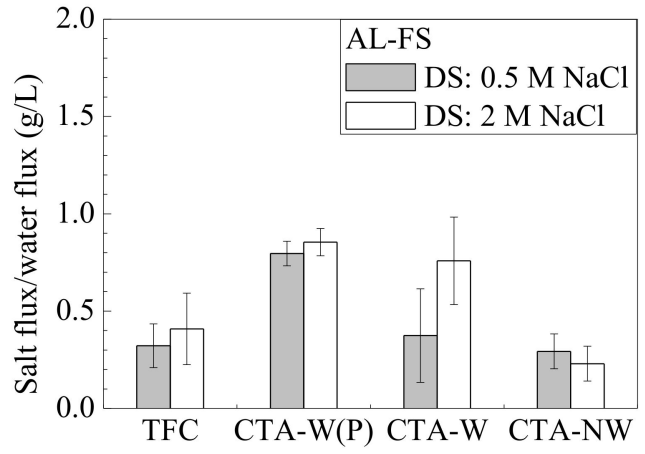

(d)

Figure A3. FO water flux and salt flux/water flux of the TFC, CTA-W(P), CTA-W, and CTA-NW membranes. Testing conditions: $10 \mathrm{mM} \mathrm{NaCl}$ as FS, and $0.5 \mathrm{M}$ or $2 \mathrm{M} \mathrm{NaCl}$ as DS.

\section{References}

1. Xue, W.; Tobino, T.; Nakajima, F.; Yamamoto, K. Seawater-driven forward osmosis for enriching nitrogen and phosphorous in treated municipal wastewater: Effect of membrane properties and feed solution chemistry. Water Res. 2015, 69, 120-130. [CrossRef]

2. Liyanaarachchi, S.; Jegatheesan, V.; Muthukumaran, S.; Gray, S.; Shu, L. Mass balance for a novel RO/FO hybrid system in seawater desalination. J. Membr. Sci. 2016, 501, 199-208. [CrossRef]

3. Phuntsho, S.; Shon, H.K.; Hong, S.; Lee, S.; Vigneswaran, S. A novel low energy fertilizer driven forward osmosis desalination for direct fertigation: Evaluating the performance of fertilizer draw solutions. J. Membr. Sci. 2011, 375, 172-181. [CrossRef]

4. Blandin, G.; Ferrari, F.; Lesage, G.; Le-Clech, P.; Héran, M.; Martinez-Lladó, X. Forward Osmosis as Concentration Process: Review of Opportunities and Challenges. Membranes 2020, 10, 284. [CrossRef]

5. Coday, B.D.; Xu, P.; Beaudry, E.G.; Herron, J.; Lampi, K.; Hancock, N.T.; Cath, T.Y. The sweet spot of forward osmosis: Treatment of produced water, drilling wastewater, and other complex and difficult liquid streams. Desalination 2014, 333, 23-35. [CrossRef]

6. Valladares Linares, R.; Li, Z.; Sarp, S.; Bucs, S.; Amy, G.; Vrouwenvelder, J.S. Forward osmosis niches in seawater desalination and wastewater reuse. Water Res. 2014, 66, 122-139. [CrossRef]

7. Ferrari, F.; Pijuan, M.; Rodriguez-Roda, I.; Blandin, G. Exploring Submerged Forward Osmosis for Water Recovery and PreConcentration of Wastewater before Anaerobic Digestion: A Pilot Scale Study. Membranes 2019, 9, 97. [CrossRef] [PubMed]

8. Phuntsho, S.; Hong, S.; Elimelech, M.; Shon, H.K. Forward osmosis desalination of brackish groundwater: Meeting water quality requirements for fertigation by integrating nanofiltration. J. Membr. Sci. 2013, 436, 1-15. [CrossRef] 
9. Blandin, G.; Verliefde, A.R.D.; Tang, C.Y.; Le-Clech, P. Opportunities to reach economic sustainability in forward osmosis-reverse osmosis hybrids for seawater desalination. Desalination 2015, 363, 26-36. [CrossRef]

10. Altaee, A.; Braytee, A.; Millar, G.J.; Naji, O. Energy efficiency of hollow fibre membrane module in the forward osmosis seawater desalination process. J. Membr. Sci. 2019, 587, 117165. [CrossRef]

11. Choi, B.G.; Zhan, M.; Shin, K.; Lee, S.; Hong, S. Pilot-scale evaluation of FO-RO osmotic dilution process for treating wastewater from coal-fired power plant integrated with seawater desalination. J. Membr. Sci. 2017, 540, 78-87. [CrossRef]

12. Wang, X.; Chang, V.W.C.; Tang, C.Y. Osmotic membrane bioreactor (OMBR) technology for wastewater treatment and reclamation: Advances, challenges, and prospects for the future. J. Membr. Sci. 2016, 504, 113-132. [CrossRef]

13. Werner, C.M.; Logan, B.E.; Saikaly, P.E.; Amy, G.L. Wastewater treatment, energy recovery and desalination using a forward osmosis membrane in an air-cathode microbial osmotic fuel cell. J. Membr. Sci. 2013, 428, 116-122. [CrossRef]

14. Helfer, F.; Lemckert, C.; Anissimov, Y.G. Osmotic power with Pressure Retarded Osmosis: Theory, performance and trends-A review. J. Membr. Sci. 2014, 453, 337-358. [CrossRef]

15. Lu, Y.; Jia, J.; Miao, H.; Ruan, W.; Wang, X. Performance Improvement and Biofouling Mitigation in Osmotic Microbial Fuel Cells via In Situ Formation of Silver Nanoparticles on Forward Osmosis Membrane. Membranes 2020, 10, 122. [CrossRef]

16. Rastogi, N.K. Opportunities and Challenges in Application of Forward Osmosis in Food Processing. Crit. Rev. Food Sci. 2016, 56, 266-291. [CrossRef] [PubMed]

17. Sant'Anna, V.; Marczak, L.D.F.; Tessaro, I.C. Membrane concentration of liquid foods by forward osmosis: Process and quality view. J. Food Eng. 2012, 111, 483-489. [CrossRef]

18. She, Q.; Wang, R.; Fane, A.G.; Tang, C.Y. Membrane fouling in osmotically driven membrane processes: A review. J. Membr. Sci. 2016, 499, 201-233. [CrossRef]

19. Tang, C.Y.; She, Q.; Lay, W.C.L.; Wang, R.; Fane, A.G. Coupled effects of internal concentration polarization and fouling on flux behavior of forward osmosis membranes during humic acid filtration. J. Membr. Sci. 2010, 354, 123-133. [CrossRef]

20. Tang, C.Y.; She, Q.; Lay, W.C.L.; Wang, R.; Field, R.; Fane, A.G. Modeling double-skinned FO membranes. Desalination 2011, 283, 178-186. [CrossRef]

21. McCutcheon, J.R.; Elimelech, M. Influence of concentrative and dilutive internal concentration polarization on flux behavior in forward osmosis. J. Membr. Sci. 2006, 284, 237-247. [CrossRef]

22. Wei, J.; Qiu, C.; Wang, Y.N.; Wang, R.; Tang, C.Y. Comparison of NF-like and RO-like thin film composite osmotically-driven membranes-Implications for membrane selection and process optimization. J. Membr. Sci. 2013, 427, 460-471. [CrossRef]

23. Cath, T.Y.; Childress, A.E.; Elimelech, M. Forward osmosis: Principles, applications, and recent developments. J. Membr. Sci. 2006, 281, 70-87. [CrossRef]

24. Wei, J.; Qiu, C.; Tang, C.Y.; Wang, R.; Fane, A.G. Synthesis and characterization of flat-sheet thin film composite forward osmosis membranes. J. Membr. Sci. 2011, 372, 292-302. [CrossRef]

25. Shibuya, M.; Yasukawa, M.; Takahashi, T.; Miyoshi, T.; Higa, M.; Matsuyama, H. Effect of operating conditions on osmotic-driven membrane performances of cellulose triacetate forward osmosis hollow fiber membrane. Desalination 2015, 362, 34-42. [CrossRef]

26. Kumano, A.; Marui, K.; Terashima, Y. Hollow fiber type PRO module and its characteristics. Desalination 2016, 389, 149-154. [CrossRef]

27. Ren, J.; McCutcheon, J.R. A new commercial thin film composite membrane for forward osmosis. Desalination 2014, 343, 187-193 [CrossRef]

28. Arena, J.T.; Manickam, S.S.; Reimund, K.K.; Brodskiy, P.; McCutcheon, J.R. Characterization and Performance Relationships for a Commercial Thin Film Composite Membrane in Forward Osmosis Desalination and Pressure Retarded Osmosis. Ind. Eng. Chem. Res. 2015, 54, 11393-11403. [CrossRef]

29. Nguyen, T.P.N.; Jun, B.M.; Lee, J.H.; Kwon, Y.N. Comparison of integrally asymmetric and thin film composite structures for a desirable fashion of forward osmosis membranes. J. Membr. Sci. 2015, 495, 457-470. [CrossRef]

30. Sahebi, S.; Phuntsho, S.; Tijing, L.; Han, G.; Han, D.S.; Abdel-Wahab, A.; Shon, H.K. Thin-film composite membrane on a compacted woven backing fabric for pressure assisted osmosis. Desalination 2017, 406, 98-108. [CrossRef]

31. Blandin, G.; Vervoort, H.; D’Haese, A.; Schoutteten, K.; Bussche, J.V.; Vanhaecke, L.; Myat, D.T.; Le-Clech, P.; Verliefde, A.R.D. Impact of hydraulic pressure on membrane deformation and trace organic contaminants rejection in pressure assisted osmosis (PAO). Process Saf. Environ. 2016, 102, 316-327. [CrossRef]

32. Xia, L.L.; Andersen, M.F.; Helix-Nielsen, C.; McCutcheon, J.R. Novel Commercial Aquaporin Flat-Sheet Membrane for Forward Osmosis. Ind. Eng. Chem. Res. 2017, 56, 11919-11925. [CrossRef]

33. Ye, W.; Lin, J.; Tækker Madsen, H.; Gydesen Søgaard, E.; Hélix-Nielsen, C.; Luis, P.; Van der Bruggen, B. Enhanced performance of a biomimetic membrane for $\mathrm{Na}_{2} \mathrm{CO}_{3}$ crystallization in the scenario of $\mathrm{CO}_{2}$ capture. J. Membr. Sci. 2016, 498, 75-85. [CrossRef]

34. Yadav, S.; Saleem, H.; Ibrar, I.; Naji, O.; Hawari, A.A.; Alanezi, A.A.; Zaidi, S.J.; Altaee, A.; Zhou, J. Recent developments in forward osmosis membranes using carbon-based nanomaterials. Desalination 2020, 482, 114375. [CrossRef]

35. Wu, W.; Shi, Y.; Liu, G.; Fan, X.; Yu, Y. Recent development of graphene oxide based forward osmosis membrane for water treatment: A critical review. Desalination 2020, 491, 114452. [CrossRef]

36. Xu, W.; Chen, Q.; Ge, Q. Recent advances in forward osmosis (FO) membrane: Chemical modifications on membranes for FO processes. Desalination 2017, 419, 101-116. [CrossRef] 
37. Zhang, S.; Wang, K.Y.; Chung, T.S.; Jean, Y.C.; Chen, H. Molecular design of the cellulose ester-based forward osmosis membranes for desalination. Chem. Eng. J. 2011, 66, 2008-2018. [CrossRef]

38. Su, J.; Yang, Q.; Teo, J.F.; Chung, T.S. Cellulose acetate nanofiltration hollow fiber membranes for forward osmosis processes. J. Membr. Sci. 2010, 355, 36-44. [CrossRef]

39. Wang, R.; Shi, L.; Tang, C.Y.; Chou, S.; Qiu, C.; Fane, A.G. Characterization of novel forward osmosis hollow fiber membranes. J. Membr. Sci. 2010, 355, 158-167. [CrossRef]

40. Yip, N.Y.; Tiraferri, A.; Phillip, W.A.; Schiffman, J.D.; Elimelech, M. High performance thin-film composite forward osmosis membrane. Environ. Sci. Technol. 2010, 44, 3812-3818. [CrossRef] [PubMed]

41. Bui, N.N.; McCutcheon, J.R. Hydrophilic nanofibers as new supports for thin film composite membranes for engineered osmosis. Environ. Sci. Technol. 2013, 47, 1761-1769. [CrossRef] [PubMed]

42. Fang, W.X.; Liu, C.; Shi, L.; Wang, R. Composite forward osmosis hollow fiber membranes: Integration of RO- and NF-like selective layers for enhanced organic fouling resistance. J. Membr. Sci. 2015, 492, 147-155. [CrossRef]

43. Setiawan, L.; Wang, R.; Shi, L.; Li, K.; Fane, A.G. Novel dual-layer hollow fiber membranes applied for forward osmosis process J. Membr. Sci. 2012, 421, 238-246. [CrossRef]

44. Saren, Q.; Qiu, C.Q.; Tang, C.Y. Synthesis and characterization of novel forward osmosis membranes based on layer-by-layer assembly. Environ. Sci. Technol. 2011, 45, 5201-5208. [CrossRef]

45. Wang, K.Y.; Chung, T.-S.; Qin, J.-J. Polybenzimidazole (PBI) nanofiltration hollow fiber membranes applied in forward osmosis process. J. Membr. Sci. 2007, 300, 6-12. [CrossRef]

46. Qi, S.R.; Li, Y.; Zhao, Y.; Li, W.Y.; Tang, C.Y.Y. Highly Efficient Forward Osmosis Based on Porous Membranes-Applications and Implications. Environ. Sci. Technol. 2015, 49, 4690-4695. [CrossRef] [PubMed]

47. Akther, N.; Phuntsho, S.; Chen, Y.; Ghaffour, N.; Shon, H.K. Recent advances in nanomaterial-modified polyamide thin-film composite membranes for forward osmosis processes. J. Membr. Sci. 2019, 584, 20-45. [CrossRef]

48. She, Q.; Zhang, L.; Wang, R.; Krantz, W.B.; Fane, A.G. Pressure-retarded osmosis with wastewater concentrate feed: Fouling process considerations. J. Membr. Sci. 2017, 542, 233-244. [CrossRef]

49. Loeb, S.; Titelman, L.; Korngold, E.; Freiman, J. Effect of porous support fabric on osmosis through a Loeb-Sourirajan type asymmetric membrane. J. Membr. Sci. 1997, 129, 243-249. [CrossRef]

50. Zhang, M.; Shan, J.; Tang, C.Y. Gypsum scaling during forward osmosis process-A direct microscopic observation study. Desalination Water Treat. 2016, 57, 3317-3327. [CrossRef]

51. Wang, Y.N.; Järvelä, E.; Wei, J.; Zhang, M.; Kyllönen, H.; Wang, R.; Tang, C.Y. Gypsum scaling and membrane integrity of osmotically driven membranes: The effect of membrane materials and operating conditions. Desalination 2016, 377, 1-10. [CrossRef]

52. She, Q.; Jin, X.; Tang, C.Y. Osmotic power production from salinity gradient resource by pressure retarded osmosis: Effects of operating conditions and reverse solute diffusion. J. Membr. Sci. 2012, 401, 262-273. [CrossRef]

53. Tang, C.Y.; Kwon, Y.-N.; Leckie, J.O. Effect of membrane chemistry and coating layer on physiochemical properties of thin film composite polyamide RO and NF membranes: I. FTIR and XPS characterization of polyamide and coating layer chemistry. Desalination 2009, 242, 149-167. [CrossRef]

54. Giagnorio, M.; Ricceri, F.; Tagliabue, M.; Zaninetta, L.; Tiraferri, A. Hybrid Forward Osmosis-Nanofiltration for Wastewater Reuse: System Design. Membranes 2019, 9, 61. [CrossRef] [PubMed]

55. Xie, M.; Gray, S.R. Gypsum scaling in forward osmosis: Role of membrane surface chemistry. J. Membr. Sci. 2016, 513, 250-259. [CrossRef]

56. She, Q.; Hou, D.; Liu, J.; Tan, K.H.; Tang, C.Y. Effect of feed spacer induced membrane deformation on the performance of pressure retarded osmosis (PRO): Implications for PRO process operation. J. Membr. Sci. 2013, 445, 170-182. [CrossRef] 